\title{
Interdependência competitiva e movimentação de alunos entre escolas: o caso da rede municipal de São Paulo (2008-2013) ${ }^{1}$
}

Antônio Augusto Gomes Batista* Gabriela Thomazinho** Paula Reis Kasmirski***

Hivy Damasio Araújo Mello****

*(Centro de Estudos e Pesquisas em Educação, Cultura e Ação Comunitária - Cenpec, São Paulo-SP, Brasil)

**(Imagem da Vida - São Paulo-SP, Brasil)

***(Fundação Getulio Vargas - FGV, São Paulo-SP, Brasil)

$\star \star \star \star \star$ (Universidade Estadual de Campinas - Unicamp, Campinas-SP, Brasil)

$\star \star \star \star \star \star$ (Instituto de Estudos Sociais e Políticos da Universidade do Estado do Rio de Janeiro - lesp/Uerj, Rio de Janeiro-RJ, Brasil)
Resumo: Este artigo analisa como se dão as trocas de escola por alunos do Ensino Fundamental da rede municipal de São Paulo, a fim de dimensionar as relações de interdependência competitiva entre escolas - compreendidas como as trocas que realizam entre si de alunos originalmente nelas matriculadas. Dados de matrícula para os anos entre 2008 e 2013 foram submetidos a três procedimentos de análise: o exame de taxas de rotatividade de alunos; a estimação da probabilidade de discentes saírem de uma escola e irem para outra por meio de painel dinâmico; e a exploração de redes sociais de escolas, por meio de modelos de Poisson. Os resultados mostram que não se identificam, na escala intrarrede, relações de interdependência competitiva, e que a setorização da matrícula, em um contexto marcado pelas desigualdades socioespaciais, como o de São Paulo, pode estar acentuando a segregação escolar ao concentrar em suas unidades populações com características sociodemográficas que tendem à homogeneidade, uma vez

${ }^{1}$ Agradecemos à Secretaria Municipal de Educação de São Paulo pela disponibilização das bases de dados, bem como pelo apoio de seus funcionários, e à Beatriz Marques Teodoro de Lima e Mitti Koyamae pela colaboração, em diferentes momentos, na organização e análise dos dados. Este estudo faz parte da pesquisa (mais ampla) "Interdependência entre escolas de territórios vulneráveis", desenvolvida em parceria entre o Centro de Estudos e Pesquisas em Educação, Cultura e Ação Comunitária (Cenpec) e a Universidade Federal de São Paulo (Unifesp), coordenada por Antônio Augusto Gomes Batista e Claudia Lemos Vóvio, respectivamente. Contou com o financiamento da Fundação Tide Setubal e do MCIT/CNPq. 
que alunos que moram em regiões mais vulneráveis acabam por estudar em escolas localizadas em áreas também mais vulneráveis.

Palavras-chave: Seleção de alunos. Desigualdades educacionais. Efeitoterritório. Interdependência competitiva entre escolas.

\section{INTRODUÇÃO}

Pesquisas têm evidenciado a existência de relações de interdependência competitiva entre escolas de um mesmo espaço ou vizinhança, que tendem a disputar especialmente alunos com melhor desempenho acadêmico e professores com melhor formação e maior experiência - o que tende a favorecer o trabalho pedagógico das escolas (VAN ZANTEN, 2001; 2005; DELVAUX; VAN ZANTEN, 2006). A intensidade dessas relações de concorrência depende da forma de regulação dos sistemas de ensino, isto é, como, por exemplo, é organizado o sistema de matrículas (em extremos, se setorizada ou aberta), bem como dos mecanismos de controle para impedir a burla do tipo de organização.

Este trabalho tem como objetivo central analisar as relações de interdependência competitiva entre escolas numa escala ampla e sob uma perspectiva quantitativa, de modo a dimensioná-las. Será considerado o caso da Rede Municipal de Ensino de São Paulo (RMESP) ${ }^{2}$, cuja regulação, dentre outras características, possui um tipo setorizado de matrícula, feita por meio de um sistema informatizado centralizado e compartilhado com a rede estadual que designa, por meio do CEP informado pelo candidato na matrícula, a escola mais próxima de sua moradia.

A pesquisa se situa no quadro das relações entre desigualdades escolares e socioespaciais (BEN AYED; BROCCOLICHI, 2008; BEN AYED, 2009, 2012; BOURDIEU, 1997; VAN ZANTEN, 2001). Grosso modo, elas destacam o papel das desigualdades sociais na construção de iniquidades educacionais, com foco prioritário nas desigualdades socioespaciais, isto é, tendo em conta em que medida o território - morar e/ou estudar em determinada localidade - influencia as questões educacionais, o que acaba por favorecer alguns e prejudicar outros. Como pressuposto tem-se que as desigualdades escolares reproduzem as desigualdades socioespaciais.

2 Era objetivo inicial desta pesquisa analisar essas relações para o conjunto da matrícula em escolas públicas do município de São Paulo, o que seria mais adequado, tendo em vista as relações existentes entre as duas redes. Porém, dificuldades de acesso aos dados de matrícula da rede estadual impossibilitaram a consecução desse objetivo. 
No Brasil, pesquisas nessa linha se dedicaram sobretudo ao exame das redes de ensino das metrópoles (ÉRNICA; BATISTA, 2012; RIBEIRO; KAZTMAN, 2008; RIBEIRO et al., 2010), contexto em que de modo mais acentuado as desigualdades socioeconômicas são objetivadas e reificadas na organização do espaço, sob a forma de segregação espacial (ÉRNICA; BATISTA, 2012). Em redes como as do Rio de Janeiro, Belo Horizonte, Curitiba e São Paulo, por exemplo, estudos apontam a associação entre as regras de matrícula nas cidades e a regulação dos sistemas e padrões de segregação escolar (COSTA; BARTHOLO, 2014)3.

Pesquisa anterior realizada em escolas públicas da zona leste do município de São Paulo, em escala microssocial, analisou como o efeito de vizinhança restringe oportunidades educacionais em territórios vulneráveis (ERNICA; BATISTA, 2012). Um dos mecanismos pelo qual esse efeito atuaria seriam as relações de interdependência competitiva entre elas, que, do ponto de vista da oferta - que é mais precisamente do que trataremos neste artigo - , se manifestam especialmente via disputa por alunos ${ }^{4}$. Unidades localizadas em regiões mais vulneráveis, em que é menor a presença do estado, teriam alunos com menores recursos culturais familiares e pior posição nessa concorrência e vice-versa. Escolas em locais menos vulneráveis imprimiriam mais facilmente exigências de comportamento e desempenho acadêmico aos alunos e, assim, poderiam pressionar os que não se adaptam a buscar outras instituições, “exteriorizando" alunos "problemáticos” ou docentes. Já escolas de regiões mais vulneráveis acumulariam desvantagens e tenderiam a ser "repositório" ou "local de decantação" dos "problemas" de outros estabelecimentos (ERNICA; BATISTA, 2012) ${ }^{5}$.

3 Costa e Bartholo (2014), ao analisarem as relações entre segregação escolar e as variáveis cor e distorção idade-série, identificaram indícios de que sistemas com livre escolha dos pais (como o do Rio de Janeiro) apresentariam menores níveis de segregação escolar do que outras redes com regras de matrícula fechadas (i.e. Curitiba) -, porém pediram cautela na interpretação dos dados, pois muitos fatores, inclusive externos às redes de ensino, como a segregação residencial, também interferem.

4 Ernica e Batista (2012) apresentaram alguns dos resultados da pesquisa "Educação em territórios de alta vulnerabilidade social na metrópole”, cujos achados embasaram a construção da pesquisa "Interdependência entre escolas de territórios vulneráveis". Vale ressaltar, porém, que a primeira pesquisa se deu em um contexto no qual o processo de matrícula ainda não estava automatizado (antes de 2011, com matrículas manuais nas DREs), isto é, mais propício para a movimentação de alunos, o que facilitava ajustes e exceções, e relações de interdependência competitiva. Com a mudança na legislação e incorporação de procedimentos baseados na automatização e centralização das matrículas, há um ganho de eficiência no processo.

A pesquisa "Educação em territórios de alta vulnerabilidade social na metrópole", realizada pelo Cenpec com o apoio da Fundação Tide Setubal e da Fapesp, envolveu uma 
Essas "trocas" de estudantes, apreendidas em escala microssocial, seriam percebidas em larga escala? Verificam-se, em escala macrossocial, estabelecimentos que "exteriorizam" e/ou que "decantam" seus "problemas" na RMESP, indicando concorrência por alunos? Em que dimensão? Dado que as desigualdades socioespaciais e escolares podem ser acentuadas pela setorização da matrícula, como é o caso de São Paulo, de que modo esses elementos se combinam? Em especial, como se combinam nesse contexto marcado pela desigualdade socioespacial e em uma rede cujo modelo de regulação, pela setorização, tende a inibir tanto as escolhas familiares quanto as práticas de seleção realizadas pelas próprias escolas? É objetivo, desse modo, explorar, na escala intrarrede, esse conjunto de hipóteses.

A pesquisa, predominantemente quantitativa, examinou dados da Secretaria Municipal da Educação (SME) referentes às matrículas do Ensino Fundamental regular de São Paulo de 2008 a 2013, fornecidos em duas bases de dados para cada ano, a nomeada como 30/04 e a nomeada como 31/12. Além dos códigos do aluno e de sua escola - que permitem acompanhar ambos ao longo do tempo -, a base de dados contém a série cursada, o status da matrícula (se ativa, transferida ou concluída), se o aluno usa transporte escolar gratuito (TEG) e seu CEP de moradia. Foram usados também microdados do Censo Escolar e da Prova Brasil, indicadores do Instituto Nacional de Estudos e Pesquisas Educacionais Anísio Teixeira (Inep) (taxa de distorção idade-série e taxas de rendimento) e dados do Índice Paulista de Vulnerabilidade Social (IPVS), versão 2010, da Fundação Seade ${ }^{6}$.

série de estudos, em escala microssocial, sobre as estratégias das escolas e das famílias relacionadas à movimentação dos alunos em uma rede de ensino. Alves et al. (2015) identificaram, no extremo leste de São Paulo, estratégias de exteriorização de alunos pelas escolas que, por conta da proibição legal, ocorriam por meio de duas práticas veladas: a negação da matrícula e a "expulsão" (ALVES et al., 2015). Batista e CarvalhoSilva pesquisaram estratégias familiares de escolha das escolas, analisando também o que é denominado pela bibliografia de "evitamento" escolar. Trata-se principalmente do evitamento de escolas determinadas por meio do programa de matrícula público e consideradas como "ruins" pelas famílias - descobriu-se que as mães hierarquizam as escolas próximas às suas moradias com base em critérios ligados a segurança, condições de ensino, benefícios sociais e perfil dos alunos (cf. BATISTA; CARVALHO-SILVA, 2013). Mais informações disponiveis sobre a pesquisa e seus resultados em: http://www. cenpec.org.br/2015/09/20/educacao-em-territorios-de-alta-vulnerabilidade-social-nametropole/.

6 Segundo a Fundação Seade (2013, p. 9), o IPVS provê "uma tipologia de situações de exposição à vulnerabilidade, agregando aos indicadores de renda outros referentes ao ciclo de vida familiar e escolaridade, no espaço intraurbano". O IPVS será usado como indicador de vulnerabilidade do território e pode assumir sete diferentes graus: 1 baixíssima; 2 muito baixa; 3 baixa; 4 média; 5 alta; 6 muito alta; 7 muito alta (setores 
Três metodologias de análise, que se complementam, foram empregadas para dimensionar as relações de interdependência competitiva entre escolas e verificar a existência, em escala, de escolas municipais que "exteriorizam" alunos que ameaçam a organização de seu cotidiano pela expulsão velada ou pela negação da matrícula. A primeira examinou taxas de rotatividade de alunos; a segunda estimou a probabilidade de discentes saírem de uma escola e irem para outra por meio de painel dinâmico; e a terceira explorou redes de relações entre escolas, por meio de modelos de Poisson. Optou-se por descrever as metodologias juntamente com a apresentação e discussão dos resultados de cada uma delas. Antes discutem-se as relações entre a setorização da matrícula e a segregação escolar.

\section{SETORIZAÇÃo E SEgREGAÇÃo}

A matrícula da rede municipal de São Paulo variou entre 531.209 e 439.628 estudantes no Ensino Fundamental entre os anos de 2008 e 2013 (vide Tabela 1).

Tabela 1 - Matrículas no Ensino Fundamental da rede municipal de São Paulo

\begin{tabular}{ccc|c|c|c|c|c|}
\hline Ano & 2008 & 2009 & 2010 & 2011 & 2012 & 2013 \\
EF1 & 271.881 & 249.317 & 233.542 & 215.946 & 210.080 & 203.726 \\
\hline EF2 & 259.328 & 251.314 & 250.898 & 248.099 & 247.697 & 235.902 \\
\hline Total & 531.209 & 500.631 & 484.440 & 464.045 & 457.777 & 439.628 \\
\hline
\end{tabular}

Fonte: Censo Escolar. Elaborado pelo Observatório do PNE.

Para analisar a relação entre setorização das matrículas e a segregação do sistema escolar municipal, utilizamos o IPVS, que categoriza cada setor censitário em uma escala de vulnerabilidade social de 1 a 7 , sendo 10 menos vulnerável e o 7 o mais vulnerável. Ao analisar a associação entre 0 IPVS das escolas municipais com o IPVS dos seus alunos (via CEP informado no cadastro de matrícula), verificamos que há correlação positiva. Em uma escola de IPVS 1, o percentual de alunos que moram em regiões com IPVS de 1 a 3 (baixa vulnerabilidade) é superior a 70\%; já em uma escola de IPVS 6, esse percentual é de $40 \%$ (vide Figura 1). Essa distribuição é estável no período analisado. Tendo em vista que, como veremos adiante, a legislação determina que se deve estudar próximo de casa, essa correlação é intuitiva - alunos que moram em localidades menos vulneráveis estudam em escola menos vulneráveis, e vice-versa. Isto é, a setorização da matrícula explica parte da segregação escolar.

rurais). Tratou-se, aqui, IPVS de 1 a 3 como baixa vulnerabilidade e 5 a 7 como alta. 
Figura 1 - Porcentagem de alunos que residem em áreas de baixa e alta vulnerabilidade por IPVS da escola - 2013

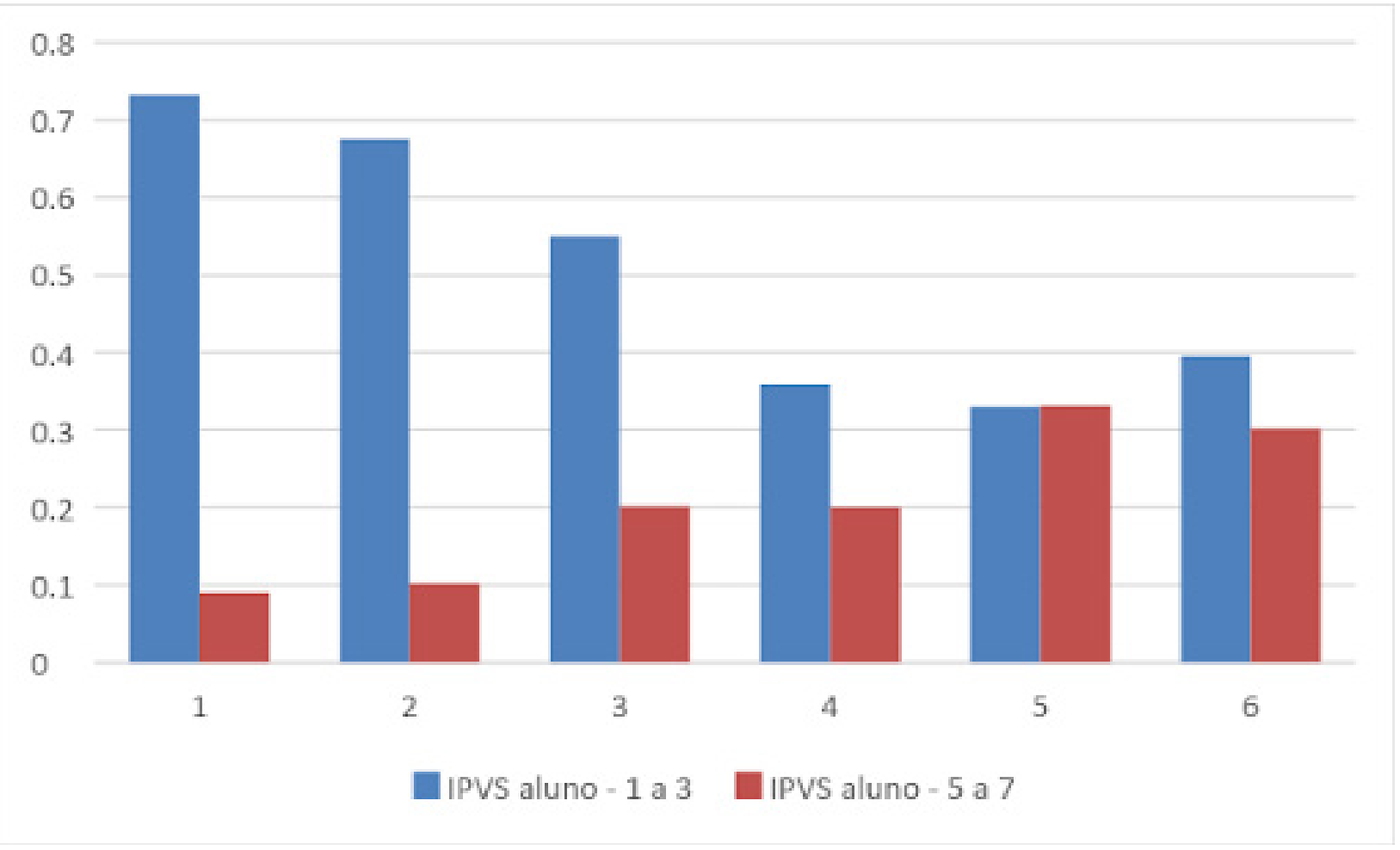

Fonte: Elaborada pelos autores com dados da SME e do Seade.

Como se vê, esse modelo de regulação, pela setorização da matrícula, tende a restringir, de certo modo, as escolhas familiares, bem como as práticas de seleção - oficiais ou veladas - realizadas pelas escolas. Dada a desigualdade socioespacial que marca a cidade de São Paulo, tal modelo tende a favorecer e reproduzir a segregação urbana ou espacial que é característica das metrópoles.

No município de São Paulo, a matrícula no Ensino Fundamental (EF) público é realizada em conjunto pelas redes municipal e estadual por meio do Programa da Matrícula Antecipada (PMA). Ele ocorre no ano anterior ao ano letivo de ingresso no fundamental público e suas regras constam em portarias conjuntas das secretarias de educação ${ }^{8}$. No programa, as escolas estaduais e municipais, incluindo as de Educação Infantil, cadastram os candidatos ao EF que devem ingressar no $1^{\circ}{ }^{\circ}$ ano ${ }^{9}$. No caso do período aqui estudado, nos

7 Não existem, na base de dados disponibilizada, escolas da Rede Municipal de São Paulo com IPVS 7, que corresponde a escolas localizadas em setores censitários rurais de vulnerabilidade alta.

8 As regras apresentadas e discutidas a seguir provêm das portarias conjuntas entre municípios e estado publicadas anualmente a partir de 2007.

9 A Lei n. 11.274, de 6 de fevereiro de 2006, ampliou o Ensino Fundamental para nove anos 
programas de matrícula de 2007, 2008 e 2009 (referentes, portanto, aos anos letivos de 2008, 2009 e 2010), os responsáveis informavam, nesse cadastro, em que região gostariam que seus filhos estudassem e seu endereço residencial. O encaminhamento da matrícula era manual e individual, realizado pelas equipes das Diretorias Municipais ou Estaduais de Educação, com base nas escolas da região indicada.

Atualmente, desde 2010 (afetando a matrícula de 2011), o encaminhamento é automático a partir do endereço indicativo do aluno ${ }^{10}$ (quando informado) ou do endereço residencial (quando não houver endereço indicativo). Na rede municipal, as matrículas ocorrem sob a coordenação das Diretorias Regionais de Educação/SME e responsabilidade das escolas municipais.

Os alunos que já estavam no Ensino Fundamental público têm, a princípio, sua matrícula garantida na mesma escola em que estavam no ano anterior e, caso mudem de endereço, a família tem direito de pedir o deslocamento da matrícula - feito antes do início do ano letivo - ou a transferência - quando as aulas já tiveram início - para uma escola mais próxima.

No período estudado - anos letivos de 2008 a 2013 -, algumas mudanças importantes ocorreram nos procedimentos de matrícula. A primeira delas é a substituição do processo manual de compatibilização das vagas feito pelas diretorias municipais e estaduais de ensino por um processo automatizado e centralizado (denominado compatibilização automática de vagas), que considera a distância a pé entre o endereço fornecido pela família do aluno e as escolas. Tal mudança, como mencionado anteriormente, aconteceu em 2010 e afetou as matrículas de 2011. A segunda mudança, que também afetou as matrículas do ano letivo de 2011 , diz respeito à introdução do endereço (CEP) indicativo no processo de cadastro dos alunos e nos pedidos de mudança de escola. Antes, o endereço usado na compatibilização das vagas era apenas 0 residencial. 0 endereço indicativo, pelo menos na legislação, pareceria aumentar as possibilidades de escolha de escola pelos pais, pois pode ser de qualquer local de interesse da família. No entanto, não foi possível avaliar os efeitos dessa mudança, pois a base de dados disponibilizada pela SME informa apenas o CEP de residência ${ }^{11}$.

de duração e estabeleceu o prazo de implantação, pelos sistemas, até 2010. A 1a série do Ensino Fundamental de oito anos é correspondente ao 1ㅇano do Ensino Fundamental de nove anos. A rede municipal de São Paulo fez a mudança em 2010.

${ }_{10} \mathrm{O}$ endereço apresentado no cadastro - efetuado em qualquer escola - pode corresponder ao de moradia ou a outro local de interesse pessoal (o do trabalho de um dos pais ou do estudante ou de um familiar, por exemplo). Na legislação, o endereço que não o de moradia é designado CEP indicativo.

${ }_{11}$ Conforme informado por funcionário da SME, os CEPs nas bases da SME são os 
Quando a distância entre o endereço do aluno (com idade até 12 anos) e a escola é maior do que 2 quilômetros - distância aferida por meio do CEP, hoje envolvendo georreferenciamento -, a prefeitura é obrigada a fornecer transporte gratuito (Programa de Transporte Escolar Municipal Gratuito - Vai e Volta; Lei n. 13.697/2003). Quando não há vaga nessas condições, o sistema de compatibilização automática não efetua o encaminhamento da matrícula e as Diretorias de Ensino fazem um encaminhamento manual, que pode incluir o aluno no Vai e Volta ou criar uma vaga em uma unidade próxima ${ }^{12}$.

RESULTADOS E DISCUSSÃO

\section{TAXAS DE ROTATIVIDADE E DE SAÍDA}

Foram calculadas, com dados da SME, do Inep e da Fundação Seade, taxas de rotatividade e de saída para checar se há maior (ou menor) movimentação de alunos em escolas de diferentes perfis, em especial de territórios vulneráveis. A taxa de rotatividade ou turnover informa a proporção de alunos substituídos por outros em relação ao total de alunos ${ }^{13}$.

A taxa de saída informa a razão das saídas da escola de um ano para outro e o número total de matrículas no ano anterior. Ela estima quantos alunos saíram da escola, independentemente de as vagas abertas serem ocupadas ou não. Por exemplo, em determinado ano, se uma escola com 100 alunos teve uma taxa de saída de $30 \%$, isso indica que 30 alunos não estavam nela matriculados no ano seguinte.

Em relação ao nosso objetivo de pesquisa e à problemática em que se situa, as taxas de rotatividade e de saída permitem apreender a extensão da

residenciais, visto que não trabalham com CEPs indicativos, esses usados somente na rotina de alocação dos candidatos.

12 De acordo com funcionário da SME. E-mail pessoal trocado em 22 de abril de 2014.

13 A taxa de rotatividade indica a razão entre o mínimo de entradas e saídas da escola (de um ano para outro) e o total de matrículas no ano-base. Ou seja, quando o número de entradas for menor que o de saídas, a taxa será dada pela divisão do número de entradas pelo total de matrículas; quando o número de saídas for menor, será a razão entre o número de saídas e o número de matrículas. Desse modo, a medida informa a proporção de alunos substituídos por outros em relação ao total de alunos. Por exemplo: em uma escola com 100 alunos em determinado ano, uma taxa de rotatividade de $30 \%$ indica que pelo menos 30 alunos deixaram a escola de um ano para o outro e que as 30 vagas abertas foram ocupadas por outros estudantes no ano $t+1$, sendo t o ano-base. A taxa terá o mesmo valor se 33 alunos deixaram a escola, mas apenas 30 vagas foram ocupadas por novos estudantes. 
movimentação de alunos, quer dizer, quanto, a partir da matrícula inicial numa unidade, os estudantes mudam de escola. Além disso, o cruzamento das taxas de rotatividade e de saída com atributos das escolas permite apreender as características das escolas que substituem e perdem mais alunos, sobretudo em relação à sua localização.

As taxas de rotatividade e de saída foram analisadas em sua tendência no tempo. As primeiras mostram uma tendência leve de aumento entre $2008 \mathrm{e}$ 2012 - o que se manifesta, na Figura 2, pela posição das caixas, que sobem ao longo do período. Em 2008, a taxa de rotatividade média das escolas era de $15 \%$ nas duas bases usadas. Em 2013, eram de $20 \%$ com base nos dados da SME e $22 \%$ nos dos Censos.

Figura 2 - Taxas de rotatividade das escolas municipais de São Paulo entre 2008 a 2012

Taxa de Rotatividade por Escola (2008 - 2012)

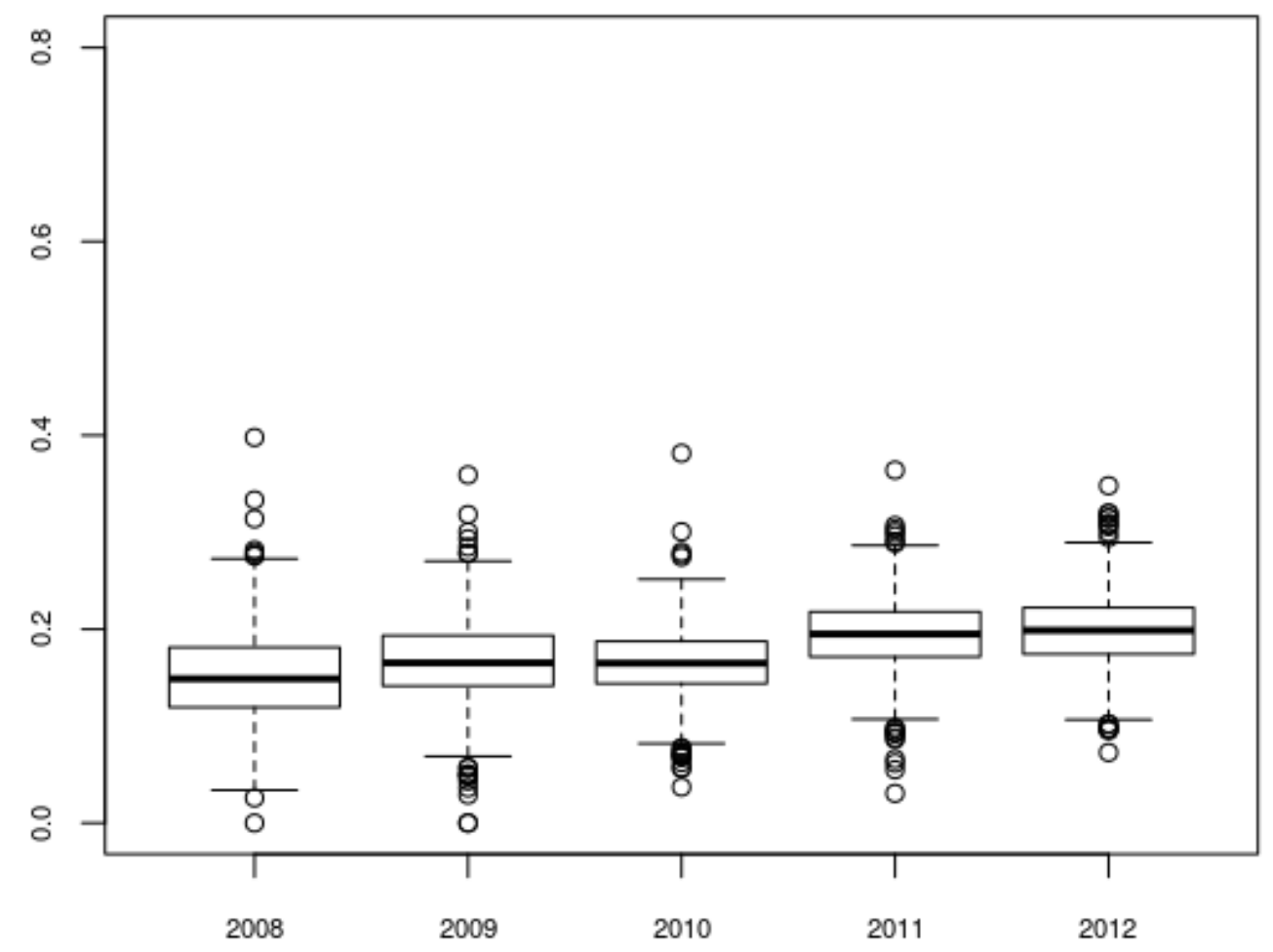

Fonte: Elaborada pelos autores com dados da SME.

A tendência de aumento da taxa de rotatividade também pode ser observada na Tabela 2. A linha correspondente à média da taxa de rotatividade se inicia, em 2008, na casa dos $15 \%$ e termina, em 2012, na casa dos $20 \%$. Houve, portanto, no período estudado, um aumento de 5 pontos percentuais (pp) na taxa de rotatividade. 
Tabela 2 - Medidas de posição e dispersão da taxa de rotatividade por escola

\begin{tabular}{cc|c|c|c|c|}
\hline & \multicolumn{5}{c}{$(2008-2012)-\%$} \\
Medida & 2008 & 2009 & 2010 & 2011 & 2012 \\
Mínimo & $3 \%$ & $7 \%$ & $8 \%$ & $11 \%$ & $11 \%$ \\
Quartil 25\% & $12 \%$ & $14 \%$ & $14 \%$ & $17 \%$ & $17 \%$ \\
Mediana & $15 \%$ & $17 \%$ & $16 \%$ & $19 \%$ & $20 \%$ \\
Quartil 75\% & $18 \%$ & $19 \%$ & $19 \%$ & $22 \%$ & $22 \%$ \\
Máximo & $27 \%$ & $27 \%$ & $25 \%$ & $29 \%$ & $29 \%$ \\
Média & $15 \%$ & $17 \%$ & $17 \%$ & $20 \%$ & $20 \%$ \\
\hline Desvio padrão & $6 \%$ & $4 \%$ & $4 \%$ & $4 \%$ & $4 \%$ \\
\hline
\end{tabular}

Fonte: Elaborada pelos autores com dados da SME.

A taxa de saída apresentava em 2008 uma maior variabilidade entre as escolas do que a taxa de rotatividade - o que diminui ao longo do tempo, como se observa na Figura 3 e na Tabela 3. A mediana se mantém constante em torno de $20 \%$.

Figura 3 - Taxas de saída das escolas municipais de São Paulo entre 2008 a 2012

Taxa de Saida por Escola (2008 - 2012)

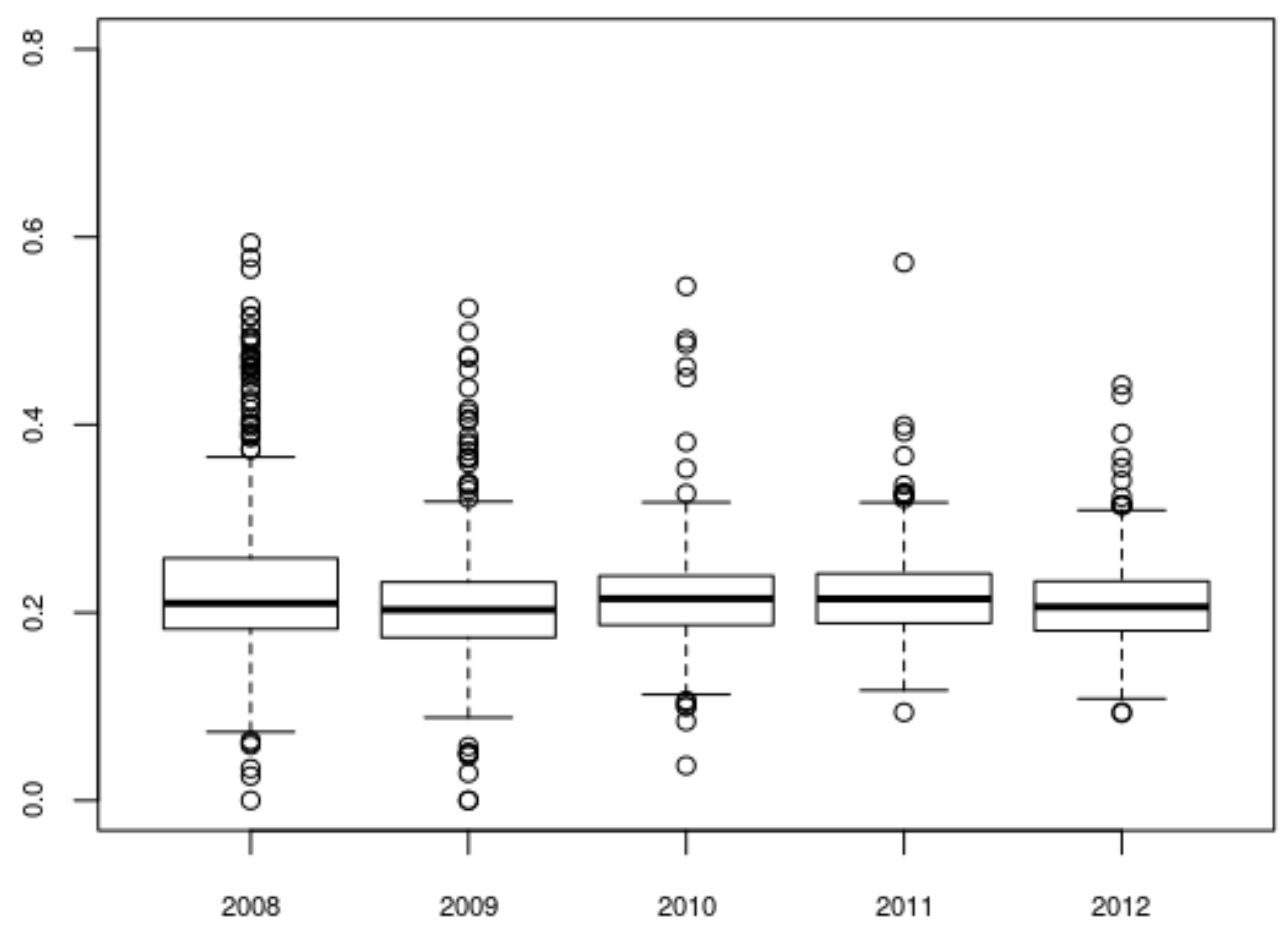

Fonte: Elaborada pelos autores com dados da SME. 
Tabela 3 - Medidas de posição e dispersão da taxa de saída por escola (2008 - 2012)

\begin{tabular}{cc|c|c|c|c|}
\hline \multirow{2}{*}{\begin{tabular}{c}
\multicolumn{5}{c}{$(2008-2012)$} \\
Medida
\end{tabular}} & 2008 & 2009 & 2010 & 2011 & 2012 \\
Mínimo & $7 \%$ & $9 \%$ & $11 \%$ & $12 \%$ & $11 \%$ \\
\hline $\begin{array}{c}\text { Quartil 25\% } \\
\text { Mediana }\end{array}$ & $18 \%$ & $17 \%$ & $19 \%$ & $19 \%$ & $18 \%$ \\
\hline Quartil 75\% & $21 \%$ & $20 \%$ & $21 \%$ & $21 \%$ & $21 \%$ \\
Máximo & $26 \%$ & $23 \%$ & $24 \%$ & $24 \%$ & $23 \%$ \\
Média & $23 \%$ & $32 \%$ & $32 \%$ & $32 \%$ & $31 \%$ \\
\hline Desvio padrão & $9 \%$ & $6 \%$ & $5 \%$ & $4 \%$ & $4 \%$ \\
\hline
\end{tabular}

Fonte: Elaborada pelos autores com dados da SME.

Para verificar se as taxas de rotatividade e de saída da RMESP seriam altas ou baixas, calculamos as taxas das redes municipais das capitais do país nos Censos e constatamos que podem ser consideradas baixas (vide Tabela 4). No Sudeste, as taxas do município de São Paulo são as menores; todas as redes municipais das capitais do Norte, Nordeste e Centro-Oeste têm taxas maiores; no Sul, somente Porto Alegre tem uma taxa menor em 2012. A taxa de saída apresenta padrão parecido. Vale dizer que as redes municipais de cada capital têm especificidades que ajudam a entender a diferença em relação à RMESP. Por exemplo, cerca de $97 \%$ das escolas municipais paulistanas ofertam todas as séries do EF. Em redes em que as escolas são organizadas de modo a separar os alunos por etapa, a rotatividade pode ser maior, pois ao final dos anos iniciais o aluno necessariamente precisa mudar de escola. Outro aspecto relevante diz respeito à regulação da matrícula, se setorizada ou não. 
Tabela 4 - Estatísticas das taxas médias de rotatividade e saída de 2008 a 2012

\begin{tabular}{|c|c|c|c|}
\hline Região & Capital & Taxa de rotatividade & Taxa de saída \\
\hline \multirow{7}{*}{ Centro-Oeste } & Campo Grande & $27,7 \%$ & $31,6 \%$ \\
\hline & Cuiabá & $34,3 \%$ & $38,9 \%$ \\
\hline & Goiânia & $38,0 \%$ & $43,0 \%$ \\
\hline & São Luís & $26,1 \%$ & $30,9 \%$ \\
\hline & Teresina & $30,0 \%$ & $34,3 \%$ \\
\hline & Fortaleza & $31,1 \%$ & $39,4 \%$ \\
\hline & Natal & $30,2 \%$ & $35,3 \%$ \\
\hline \multirow[t]{8}{*}{ Nordeste } & João Pessoa & $33,4 \%$ & $39,1 \%$ \\
\hline & Recife & $30,9 \%$ & $37,7 \%$ \\
\hline & Maceió & $30,1 \%$ & $36,2 \%$ \\
\hline & Aracaju & $30,9 \%$ & $36,6 \%$ \\
\hline & Salvador & $33,6 \%$ & $40,2 \%$ \\
\hline & Porto Velho & $33,7 \%$ & $38,8 \%$ \\
\hline & Rio Branco & $37,9 \%$ & $43,4 \%$ \\
\hline & Amazonas & $33,5 \%$ & $40,2 \%$ \\
\hline \multirow[t]{5}{*}{ Norte } & Boa Vista & $43,9 \%$ & $47,3 \%$ \\
\hline & Belém & $28,5 \%$ & $32,5 \%$ \\
\hline & Macapá & $30,8 \%$ & $35,6 \%$ \\
\hline & Palmas & $40,0 \%$ & $45,3 \%$ \\
\hline & Belo Horizonte & $25,5 \%$ & $30,2 \%$ \\
\hline \multirow{4}{*}{ Sudeste } & Vitória & $23,7 \%$ & $27,2 \%$ \\
\hline & Rio de Janeiro & $29,2 \%$ & $34,2 \%$ \\
\hline & São Paulo & $18,7 \%$ & $24,9 \%$ \\
\hline & Curitiba & $30,9 \%$ & $34,6 \%$ \\
\hline \multirow[t]{2}{*}{ Sul } & Florianópolis & $27,8 \%$ & $31,6 \%$ \\
\hline & Porto Alegre & $22,3 \%$ & $25,5 \%$ \\
\hline
\end{tabular}

Fonte: Elaborada pelos autores com dados do Inep.

Uma análise desses dados por diferentes fatores intervenientes mostra que não há diferenças substanciais entre DREs. As figuras 4 e 5 mostram as taxas de rotatividade e de saída por diretoria de ensino para o ano de 2012. 
BATISTA, Antônio Augusto Gomes; THOMAZINHO, Gabriela; KASMIRSKI, Paula Reis;

MELLO, Hivy Damasio Araújo; GUARNIERI, Fernando Henrique Eduardo.

Figura 4 - Taxa de rotatividade por diretoria de ensino para o ano de 2012

Distribuição da Taxa de Rotatividade por diretoria - 2012

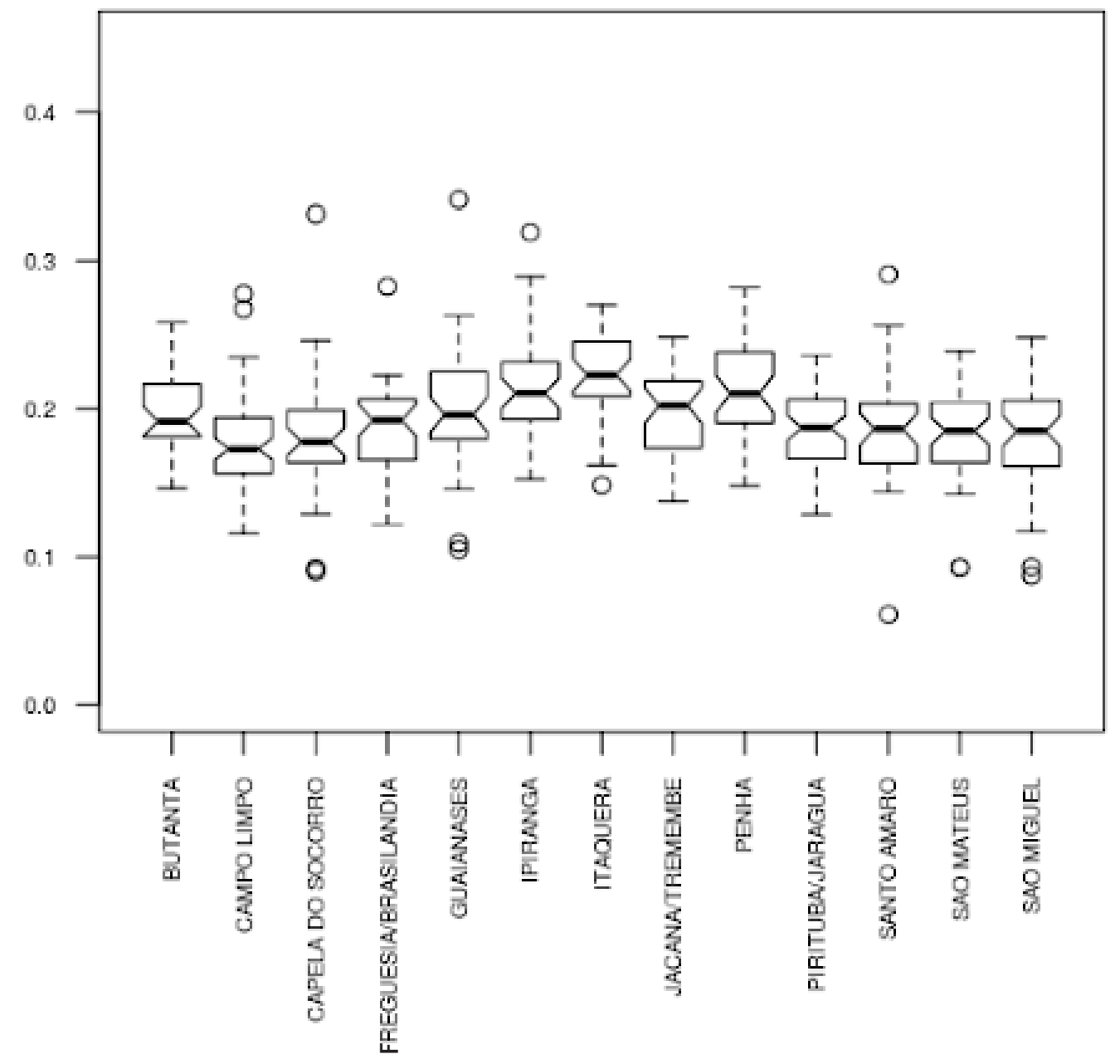

Fonte: Elaborada pelos autores com dados da SME. 


\section{Distribuição da Taxa de Saída por diretoria - 2012}

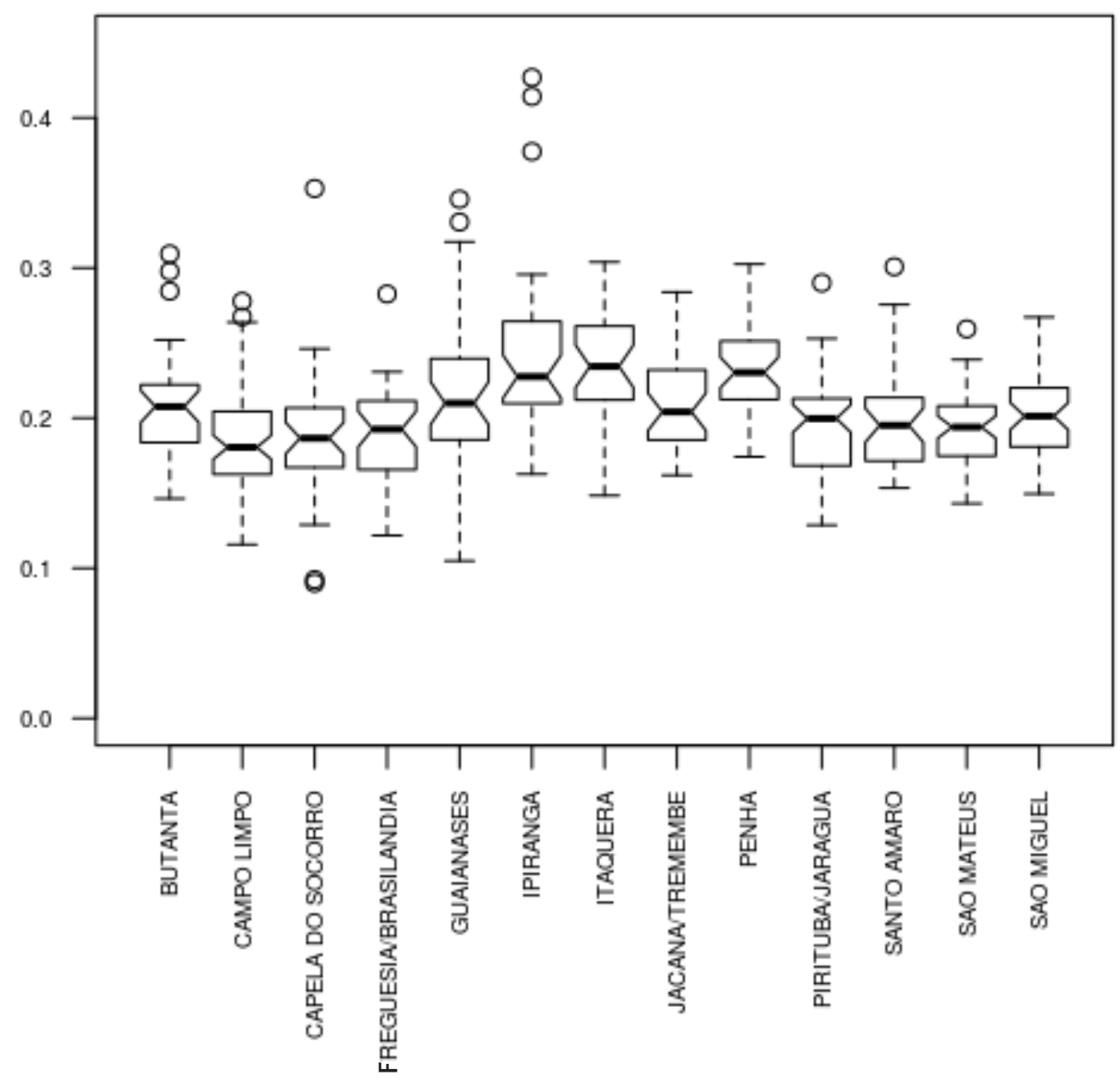

Fonte: Elaborada pelos autores com dados da SME.

Assim como a taxa de rotatividade geral por ano, a taxa de saída por diretoria não apresenta grande variação, o que é ratificado pela sobreposição dos “dentes” dos gráficos das figuras 4 e 5 , que dão um “intervalo de confiança” em torno da mediana. Há uma pequena preponderância das diretorias do Ipiranga, de Itaquera e da Penha entre as que mais substituem alunos. 0 mesmo pode ser visto para a taxa de saída, conforme a Figura 5. Nos outros anos a situação é a mesma.

No período estudado, na RMESP, em média $75,7 \%$ dos alunos que saem de uma escola municipal migram para outra rede, como podemos verificar na Tabela 5. Esses dados não consideram o 90 ano, quando seria compreensível a mudança, já que o Ensino Médio não é ofertado pela rede municipal. Não é possível saber para qual rede - se estadual ou privada - o aluno migrou. Dado o percentual de migração entre redes, o estudo acabou por tratar apenas 
dos restantes (em média, 24,3\% dos alunos), que são os que trocam de escola e permanecem na RMESP. Talvez as relações de interdependência mais fortes sejam entre escolas de diferentes redes ou entre redes de ensino. Como não foi possível, nos prazos da pesquisa, ter acesso aos dados da rede estadual de ensino, não houve condições de realizar uma análise dessas relações que, certamente, merecem estudos posteriores.

Tabela 5 - Alunos do EF que saíram de suas escolas de um ano para outro, desconsiderando os alunos de $8^{\circ}$ série $/ 9^{\circ}$ ano*

\begin{tabular}{|c|c|c|c|c|c|}
\hline \multirow[t]{2}{*}{ Transição } & \multirow{2}{*}{$\begin{array}{c}\text { Total de alunos do EF } \\
\text { que saíram de suas } \\
\text { escolas }\end{array}$} & \multicolumn{2}{|c|}{$\begin{array}{l}\text { Saíram da escola e } \\
\text { deixaram a RMESP }\end{array}$} & \multicolumn{2}{|c|}{$\begin{array}{c}\text { Saíram da escola } \\
\text { e ficaram na } \\
\text { RMESP }\end{array}$} \\
\hline & & $\begin{array}{l}\text { № de } \\
\text { alunos }\end{array}$ & $\%$ & $\begin{array}{l}\text { № de } \\
\text { alunos }\end{array}$ & $\%$ \\
\hline $2008 / 2009$ & 80.682 & 53.871 & 66,8 & 26.811 & 33,2 \\
\hline $2009 / 2010$ & 63.392 & 46.496 & 73,4 & 16.896 & 26,7 \\
\hline $2010 / 2011$ & 55.786 & 45.743 & 82,0 & 10.043 & 18,0 \\
\hline $2011 / 2012$ & 53.159 & 42.080 & 79,2 & 11.079 & 20,8 \\
\hline $2012 / 2013$ & 55.807 & 43.077 & 77,2 & 12.730 & 22,8 \\
\hline Média & & & 75,7 & & 24,3 \\
\hline
\end{tabular}

Fonte: Elaborada pelos autores com dados do Inep.

Dentre os que saem de uma escola sem deixar a rede municipal, em média $40 \%$ mudam de endereço (Tabela 6).

Tabela 6 - Alunos do EF (desconsiderando alunos de $8^{\circ}$ série $/ 9^{\circ}$ ano*) que saíram de suas escolas de um ano para outro, segundo mudança de CEP

\begin{tabular}{|c|c|c|c|c|c|}
\hline \multirow[b]{2}{*}{ Transição } & \multirow{2}{*}{$\begin{array}{c}\text { Total que saiu da } \\
\text { sua escola e ficou na } \\
\text { RMESP }\end{array}$} & \multicolumn{2}{|c|}{ Mudou de CEP } & \multicolumn{2}{|c|}{ Não mudou de CEP } \\
\hline & & $\begin{array}{l}\text { № de } \\
\text { alunos }\end{array}$ & $\%$ & $\begin{array}{l}\text { № de } \\
\text { alunos }\end{array}$ & $\%$ \\
\hline $2008 / 2009$ & 26.811 & 6.009 & 22,4 & 20.802 & 77,6 \\
\hline $2009 / 2010$ & 16.896 & 7.344 & 43,5 & 9.552 & 56,5 \\
\hline $2010 / 2011$ & 10.043 & 5.037 & 50,2 & 5.006 & 49,8 \\
\hline $2011 / 2012$ & 11.079 & 5.656 & 51,1 & 5.423 & 48,9 \\
\hline $2012 / 2013$ & 12.730 & 4.208 & 33,1 & 8.522 & 66,9 \\
\hline Média & 15.512 & & 40,0 & & 60,0 \\
\hline
\end{tabular}

Fonte: Elaborada pelos autores com dados da SME. 
Ainda, se olharmos para o mesmo conjunto de alunos que saíram da escola e ficaram na RMESP, vemos que deles $10 \%$ repetem de série ou ano (vide Tabela 7).

Tabela 7 - Repetência de alunos do EF que saíram de suas escolas de um ano para outro e que ficaram na rede, desconsiderando alunos de $8^{0}$ série $/ 9^{\circ}$ ano

\begin{tabular}{|c|c|c|c|c|}
\hline \multirow[t]{3}{*}{ Transição } & \multicolumn{4}{|c|}{ Saíram da escola e ficaram na RMESP } \\
\hline & \multicolumn{2}{|c|}{ Não repetiu } & \multicolumn{2}{|c|}{ Repetiu } \\
\hline & Número de alunos & $\begin{array}{l}\text { \% entre os } \\
\text { que saíram } \\
\text { e ficaram na } \\
\text { rede }\end{array}$ & $\begin{array}{c}\text { Número } \\
\text { de } \\
\text { alunos }\end{array}$ & $\begin{array}{l}\text { \% entre os } \\
\text { que saíram } \\
\text { e ficaram na } \\
\text { rede }\end{array}$ \\
\hline $2008 / 2009$ & 24.506 & 91.4 & 2.305 & 8,6 \\
\hline $2009 / 2010$ & 15.239 & 90.2 & 1.657 & 9,8 \\
\hline $2010 / 2011$ & 8.892 & 88.5 & 1.151 & 11,5 \\
\hline 2011/2012 & 9.898 & 89.3 & 1.181 & 10,7 \\
\hline $2012 / 2013$ & 11.508 & 90.4 & 1.222 & 9,6 \\
\hline
\end{tabular}

Fonte: Elaborada pelos autores com dados da SME.

Em relação aos alunos que chegaram a uma escola, os dados são bem parecidos: $72 \%$ vêm de outra rede e, entre os que chegaram e já estavam na rede municipal, em média, $40 \%$ mudaram de endereço e $11 \%$ repetiram (tabelas 8 e 9).

Tabela 8 - Alunos que chegaram às escolas de um ano para outro, desconsiderando alunos de $1^{0}$ série ou $1^{\circ}$ ano

\begin{tabular}{|c|c|c|c|c|c|c|}
\hline \multirow[b]{3}{*}{ Transição } & \multirow{2}{*}{\multicolumn{2}{|c|}{$\begin{array}{c}\text { Chegou à rede } \\
\text { municipal }\end{array}$}} & \multicolumn{4}{|c|}{ Já estava na rede municipal } \\
\hline & & & \multicolumn{2}{|c|}{ Mudou de CEP } & \multicolumn{2}{|c|}{ Não mudou de CEP } \\
\hline & $\begin{array}{l}\text { Número } \\
\text { de alunos }\end{array}$ & $\begin{array}{c}\text { \% entre } \\
\text { os que } \\
\text { chegaram }\end{array}$ & $\begin{array}{l}\text { Número } \\
\text { de alunos }\end{array}$ & $\begin{array}{c}\% \text { entre } \\
\text { os que } \\
\text { chegaram }\end{array}$ & $\begin{array}{c}\text { Número de } \\
\text { alunos }\end{array}$ & $\begin{array}{c}\text { \% entre } \\
\text { os que } \\
\text { chegaram }\end{array}$ \\
\hline 2008-2009 & 34.684 & 56,0 & 6.058 & 9,8 & 21.191 & 34,2 \\
\hline 2009-2010 & 41.394 & 70,7 & 7.441 & 12,7 & 9.680 & 16,5 \\
\hline $2010-2011$ & 32.799 & 76,3 & 5.060 & 11,8 & 5.108 & 11,9 \\
\hline 2011-2012 & 45.012 & 80,0 & 5.716 & 10,2 & 5.509 & 9,8 \\
\hline 2012-2013 & 47.075 & 78,4 & 4.259 & 7,1 & 8.718 & 14,5 \\
\hline
\end{tabular}

Fonte: Elaborada pelos autores com dados da SME. 
BATISTA, Antônio Augusto Gomes; THOMAZINHO, Gabriela; KASMIRSKI, Paula Reis; MELLO, Hivy Damasio Araújo; GUARNIERI, Fernando Henrique Eduardo.

Tabela 9 - Repetência de alunos que chegaram às escolas de um ano para outro e que já estavam na rede, desconsiderando alunos de $1^{0}$ série ou $1^{\circ}$ ano

\begin{tabular}{|c|c|c|c|c|}
\hline \multirow[b]{3}{*}{ Transição } & \multicolumn{4}{|c|}{ Já estava na rede municipal } \\
\hline & & Não repetiu & & Repetiu \\
\hline & $\begin{array}{l}\text { Número } \\
\text { de alunos }\end{array}$ & $\begin{array}{c}\text { \% entre os que } \\
\text { chegaram e já estavam } \\
\text { na rede }\end{array}$ & $\begin{array}{l}\text { Número de } \\
\text { alunos }\end{array}$ & $\begin{array}{c}\% \text { entre os que } \\
\text { chegaram e já estavam } \\
\text { na rede }\end{array}$ \\
\hline 2008-2009 & 24.506 & 89,9 & 2.743 & 10,1 \\
\hline 2009-2010 & 15.239 & 89,0 & 1.882 & 11,0 \\
\hline 2010-2011 & 8.892 & 87,5 & 1.276 & 12,6 \\
\hline 2011-2012 & 9.898 & 88,2 & 1.327 & 11,8 \\
\hline 2012-2013 & 11.508 & 88,7 & 1.469 & 11,3 \\
\hline
\end{tabular}

Fonte: Elaborada pelos autores com dados da SME.

Portanto, a análise das taxas de rotatividade e de saída aponta que 50\% das mudanças de escola internas à rede podem estar relacionadas à mudança de endereço ou repetência. Restam, porém, dentre os alunos que mudaram de escola, $50 \%$ dos alunos. Para analisar fatores que intervêm na migração para outras escolas, foi realizada uma análise de dados por um modelo de painel dinâmico.

\section{MODELOS DE PAINEL DINÂMICO}

Modelos de painel dinâmico ${ }^{14}$ têm natureza longitudinal, em que se acompanha um mesmo grupo de alunos ao longo do tempo, e nesta pesquisa foram utilizados para testar a hipótese de que há "externalização" 15 de alunos na RMESP. Parte da literatura que estuda esses fenômenos sociais reporta que alunos mudam de escola por iniciativa da família (na busca de uma escola mais adequada às necessidades da criança ou de maior qualidade; devido à

14 Um modelo dinâmico é aquele em que as variáveis passadas influenciam o futuro. Nesse modelo, usamos os dados de vários anos para acompanhar a trajetória dos estudantes, utilizando um modelo para dados longitudinais em que os alunos são acompanhados ao longo do tempo. Por meio do efeito fixo do aluno, é possível controlar todas as características que não mudam no tempo e que influenciam a escolha na troca de escola. A inclusão de efeitos fixos no tempo inclui os efeitos de variáveis omitidas que variam entre os alunos, mas que permanecem constantes para cada estudante.

15 Mecanismos de externalização-decantação são aqui compreendidos como processos de seleção de alunos. Escolas com maior atratividade tenderiam a evitar os alunos menos adequados a seus ideais e esses seriam enviados para escolas próximas de menor atratividade que, sem condições de selecionar, acabam por “decantar”/concentrar justamente esses alunos. 
ocorrência de problemas familiares - i.e., saúde, divórcio e desemprego -; por conta de mudança de residência, cf. HANUSHEK et al., 2004) ou da escola (indiretamente, por meio de políticas e práticas que forçam o estudante a se desengajar e migrar voluntariamente; e/ou diretamente, via políticas e decisões de suspender, expulsar ou transferir compulsoriamente o aluno, porque ele tira notas baixas, falta muito, é tido como indisciplinado ou está com alta defasagem idade-série, RUMBERGER, 2003; ALVES et al., 2018). Não dispomos de dados oficiais sobre o que motivou a mudança de escola, de modo que a análise dos padrões de movimentação e características dos alunos que migram e escolas que doam/recebem alunos é o que pode nos fornecer elementos para compreender os processos de trocas de escolas na RMESP.

Para analisar os padrões de movimentação, utilizamos como variáveis dependentes as probabilidades de um aluno sair e de chegar a uma escola. Como variáveis explicativas (ou covariadas) desse modelo, isto é, que podem estar associadas ao fenômeno, temos características discentes e escolares apontadas pela literatura como relevantes para explicar a troca de escola, a saber: variável que indica se o aluno trocou de escola no período anterior; características do aluno que variam no tempo (IPVS da moradia ${ }^{16}$, se mudou de endereço, se repetiu de ano e se usa transporte escolar gratuito - TEG); características da escola de que ele partiu ou a que chegou (IPVS da escola e distorção idade-série ${ }^{17}$ ); dummies ${ }^{18}$ de ano e de Diretoria Regional de Ensino (DRE); e um efeito fixo do aluno (características dos alunos fixas no tempo, como raça, sexo, se cursou Educação Infantil, etc ${ }^{19}$.). Para investigar as hipóteses de pesquisa, foram incluídas as interações de dummies de cada nível de IPVS da escola com a dummy que indica se o aluno repetiu de ano. Apresentamos a forma funcional do modelo no Apêndice I.

${ }_{16}$ O IPVS de moradia é tido como proxy do nível socioeconômico do aluno. Uma variável proxy é usada como substituta para uma outra variável de interesse que não pode ser observada ou medida. A variável proxy não é relevante por si mesma, mas pela correlação que ela tem com a variável de interesse.

${ }_{17}$ A taxa de distorção idade-série dos alunos de EF é nosso controle para qualidade da escola.

18 Uma variável dummy é uma variável binária atribuída ao valor 1 ou 0 para indicar a presença ou ausência de determinada característica. Por exemplo, se o ano em questão é 2010, a variável dummy de 2010 terá valor 1 e as dummys de todos os outros anos terão valor 0 .

19 Como dito, por meio do efeito fixo do aluno, é possível controlar todas as características fixas no tempo (isto é, que não mudam no tempo considerado, como raça, sexo, se cursou Educação Infantil, escolaridade da mãe) e que tendem a influenciar a escolha de trocar de escola. A inclusão de efeitos fixos no tempo inclui os efeitos de variáveis omitidas que variam entre os alunos, mas que permanecem constantes para cada estudante ao longo do tempo. 
As interações do IPVS da escola com a repetência do aluno são responsáveis por capturar se o efeito de repetir de ano varia de acordo com o IPVS da escola onde o aluno estuda. Por meio das interações podemos comparar os efeitos marginais da reprovação para escolas de diferentes níveis de vulnerabilidade, dado pelo impacto da variável de reprovação sobre a probabilidade de saída. Isto é, comparamos o que acontece com a probabilidade de saída ou de entrada em escolas similares, do mesmo grupo de IPVS, quando há uma variação da taxa de repetência, o que é chamado de efeito marginal.

No modelo para a probabilidade de saída, se o efeito marginal da reprovação for maior em escolas de baixa vulnerabilidade (IPVS 1 a 3), isso seria consistente com uma situação em que instituições de regiões menos vulneráreis pressionam alunos que não se adaptam a buscar outras unidades. No modelo que explica a probabilidade de chegada, se o efeito marginal da reprovação for maior em escolas de alta vulnerabilidade (IPVS 5 e 6), teríamos indícios de que estabelecimentos de locais mais vulneráveis seriam o repositório dos alunos externalizados pelas demais escolas.

Analisamos quatro coortes - ingressantes no EF em 2008 e em 2009 e alunos que cursavam a 4⿳亠口 série em 2008 e $2009^{20}$-, permitindo assim um acompanhamento da trajetória do aluno por um período de tempo. Usamos a subamostra de alunos que permaneceram na RMESP no período; quando o aluno deixa a rede, perdem-se informações como a repetência ${ }^{21}$.

Por meio do modelo dinâmico, buscamos examinar que fatores escolares e extraescolares estão associados às mudanças de escola por um aluno. Buscamos investigar se a movimentação está associada às trocas de escola por alunos com melhores perfis acadêmicos, por exemplo, ou por estudantes com pior desempenho ou com problemas de ajustamento às expectativas escolares, o que poderia indicar um evitamento, pelas escolas, de alunos com esse perfil. Também é possível investigar se fatores como localização da escola ou sua composição socioeconômica interferem nessas relações de interdependência - por exemplo, estar localizada num entorno mais vulnerável socialmente implica receber alunos evitados por outras escolas, como alunos repetentes. Como se trata de painel, tudo isso será visto ao longo do tempo, e tendo como referência um mesmo grupo de alunos.

20 As coortes de 2009 permitem o uso de uma variável defasada (quando uma variável de $\mathrm{t}-1$ - ano anterior - influencia a variável dependente do ano t; as coortes de 2008 permitem o uso de uma variável com a defasagem de um ou dois anos.

${ }^{21}$ Como veremos, desconsiderando alunos de $8^{\mathrm{a}}$ série/9으 ano, em média $76 \%$ dos alunos que trocam de escola no período saem da RMESP (migram para outra rede). 
Primeiro calculamos o efeito da repetência sobre a probabilidade de trocar de escola, revelando que esse fator é importante para explicar a troca. Os resultados revelam que se o aluno repetiu de ano, as chances de sair da escola aumentam de 2 a 7,5 pontos percentuais (Tabela 10). Outras covariadas com efeitos significativos sobre a probabilidade de sair da escola são a mudança de CEP e se o aluno usa TEG, o que indica que o endereço do aluno e a distância da casa até a escola são fatores que influenciam a migração entre escolas.

Tabela 10 - Regressões - painel dinâmico - probabilidade de sair da escola - sem interações

\begin{tabular}{|c|c|c|c|c|c|c|c|c|}
\hline \multirow{3}{*}{$\begin{array}{l}\text { Covariadas } \\
\text { Mudou de escola no ano anterior } \\
\text { IPVS da escola: } 0\end{array}$} & \multicolumn{2}{|c|}{ Coorte 1} & \multicolumn{2}{|c|}{ Coorte 2} & \multicolumn{2}{|c|}{ Coorte 3} & \multicolumn{2}{|c|}{ Coorte 4} \\
\hline & 0,005 & & $-0,001$ & & $-0,003$ & & 0,001 & \\
\hline & 0,046 & & 0,069 & & $-0,208$ & & $-0,271$ & * \\
\hline IPVS da escola: 2 & 0,108 & & 0,110 & & 0,036 & & $-0,136$ & \\
\hline IPVS da escola: 3 & 0,104 & & 0,034 & & 0,061 & & $-0,196$ & ** \\
\hline IPVS da escola: 4 & $-0,114$ & & 0,194 & & $-0,233$ & * & $-0,367$ & 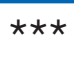 \\
\hline IPVS da escola: 5 & 0,117 & & 0,091 & & 0,083 & & $-0,082$ & \\
\hline IPVS da escola: 6 & 0,540 & $\star \star \star$ & 0,203 & & 0,023 & & $-0,153$ & \\
\hline Aluno repetiu de ano & 0,020 & 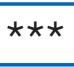 & 0,075 & $\star \star \star$ & 0,049 & $\star \star \star$ & 0,027 & $\star \star \star *$ \\
\hline Taxa de distorção idade-série do EF & $-0,002$ & 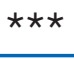 & 0,000 & & $-0,001$ & & $-0,002$ & 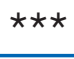 \\
\hline Aluno mudou de CEP & 0,114 & $\star \star \star$ & 0,150 & $\star \star \star$ & 0,101 & 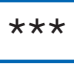 & 0,111 & $\star \star \star$ \\
\hline Aluno usa TEG & 0,052 & 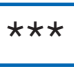 & 0,046 & $\star \star \star *$ & 0,030 & 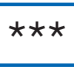 & 0,028 & 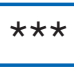 \\
\hline IPVS do aluno: 0 & 0,045 & & 0,028 & & $-0,007$ & & 0,003 & \\
\hline IPVS do aluno: 2 & 0,016 & & 0,060 & $\star \star$ & $-0,019$ & & $-0,007$ & \\
\hline IPVS do aluno: 3 & 0,035 & & 0,037 & & $-0,014$ & & $-0,003$ & \\
\hline IPVS do aluno: 4 & 0,034 & & 0,070 & $\star \star$ & 0,003 & & $-0,001$ & \\
\hline IPVS do aluno: 5 & 0,039 & * & 0,041 & & $-0,008$ & & 0,005 & \\
\hline IPVS do aluno: 6 & 0,031 & & 0,037 & & 0,001 & & $-0,007$ & \\
\hline IPVS do aluno: 7 & 0,080 & * & $-0,073$ & $\star \star$ & 0,109 & $\star \star \star$ & 1,090 & 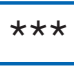 \\
\hline
\end{tabular}

Fonte: Elaborada pelos autores com dados da SME.

Notas: Todas as regressões contêm efeitos fixos de DRE e ano. Coorte 1: ingressantes no EF em 2008; coorte 2: ingressantes no EF em 2009; coorte 3: alunos que cursavam a $4^{\text {a }}$ série em 2008; coorte 4: alunos que cursavam a $4^{\underline{a}}$ série em 2009.

*** Coeficiente significativo a $1 \%$. ${ }^{* \star}$ Coeficiente significativo a $5 \%$. ${ }^{*}$ Coeficiente significativo a $10 \%$. Todos os outros coeficientes não são significativos.

A repetência também afeta a probabilidade de chegar a uma escola. Se o aluno repetiu de ano, as chances de chegar a uma escola aumentam entre 2,1 e 6,8 pontos percentuais (Tabela 11). Esse resultado é preocupante, pois além 
BATISTA, Antônio Augusto Gomes; THOMAZINHO, Gabriela; KASMIRSKI, Paula Reis;

MELLO, Hivy Damasio Araújo; GUARNIERI, Fernando Henrique Eduardo.

dos efeitos negativos da reprovação sobre o aluno (REBELO, 2009; FERRÃO, 2015), o repetente está sujeito a lidar também com custos de adaptação à nova escola (HANUSHEK et al., 2004). Novamente, a mudança de CEP e o uso de TEG são fatores com forte associação com a migração entre escolas.

Tabela 11 - Fatores que influenciam a probabilidade de entrada em uma escola sem interações

\begin{tabular}{|c|c|c|c|c|c|c|c|c|}
\hline Covariadas & \multicolumn{2}{|c|}{ Coorte 1} & \multicolumn{2}{|c|}{ Coorte 2} & \multicolumn{2}{|c|}{ Coorte 3} & \multicolumn{2}{|c|}{ Coorte 4} \\
\hline $\begin{array}{c}\text { Mudou de escola no ano } \\
\text { anterior }\end{array}$ & 0,012 & $\star \star \star ~$ & $-0,006$ & & 0,004 & & 0,009 & $\star \star \star$ \\
\hline IPVS da escola: 0 & 0,047 & & $-0,242$ & & 0,100 & & 0,090 & \\
\hline IPVS da escola: 2 & $-0,031$ & & $-0,152$ & & $-0,023$ & & 0,150 & * \\
\hline IPVS da escola: 3 & $-0,182$ & * & $-0,134$ & & $-0,070$ & & 0,174 & ** \\
\hline IPVS da escola: 4 & $-0,082$ & & $-0,268$ & ** & $-0,018$ & & 0,127 & \\
\hline IPVS da escola: 5 & $-0,039$ & & $-0,085$ & & $-0,068$ & & 0,162 & * \\
\hline IPVS da escola: 6 & $-0,473$ & $\star \star \star *$ & $-0,595$ & $\star \star \star ~$ & 0,025 & & 0,234 & $\star \star$ \\
\hline Aluno repetiu de ano & 0,021 & 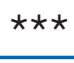 & 0,068 & $\star \star \star$ & 0,049 & $\star \star \star *$ & 0,028 & $\star \star \star$ \\
\hline $\begin{array}{c}\text { Taxa de distorção idade- } \\
\text { série do EF }\end{array}$ & 0,005 & $\star \star \star *$ & 0,017 & $\star \star \star$ & 0,000 & & $-0,002$ & $\star \star \star *$ \\
\hline Aluno mudou de CEP & 0,107 & $\star \star \star$ & 0,150 & $\star \star \star$ & 0,097 & 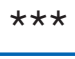 & 0,107 & $\star \star \star$ \\
\hline Aluno usa TEG & $-0,044$ & 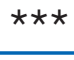 & $-0,019$ & $\star \star \star$ & $-0,017$ & $\star \star \star$ & $-0,041$ & $\star \star \star *$ \\
\hline IPVS do aluno: 0 & 0,063 & & $-0,095$ & & $-0,017$ & & $-0,026$ & \\
\hline IPVS do aluno: 2 & 0,027 & & $-0,040$ & & $-0,024$ & & $-0,004$ & \\
\hline IPVS do aluno: 3 & 0,026 & & 0,003 & & $-0,032$ & & $-0,013$ & \\
\hline IPVS do aluno: 4 & 0,028 & & $-0,016$ & & $-0,035$ & & $-0,013$ & \\
\hline IPVS do aluno: 5 & 0,025 & & $-0,023$ & & $-0,047$ & & $-0,023$ & \\
\hline IPVS do aluno: 6 & 0,015 & & $-0,007$ & & $-0,019$ & & $-0,007$ & \\
\hline IPVS do aluno: 7 & 0,135 & 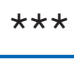 & 0,121 & $\star \star \star$ & 0,000 & & 0,914 & $\star \star \star$ \\
\hline
\end{tabular}

Fonte: Elaborada pelos autores com dados da SME.

Notas: Todas as regressões contêm efeitos fixos de DRE e ano. Coorte 1: ingressantes no EF em 2008; coorte 2: ingressantes no EF em 2009; coorte 3: alunos que cursavam a $4^{\underline{a}}$ série em 2008; coorte 4: alunos que cursavam a $4^{\underline{a}}$ série em 2009.

*** Coeficiente significativo a $1 \%$. ${ }^{* *}$ Coeficiente significativo a $5 \%$. ${ }^{\star}$ Coeficiente significativo a $10 \%$. Todos os outros coeficientes não são significativos.

Para observar se há externalização ou decantação de alunos repetentes em escolas mais vulneráveis, incluímos as interações entre IPVS e repetência no modelo. Conforme dito anteriormente, se o efeito marginal da reprovação sobre a probabilidade de saída do aluno for maior em escolas de baixa 
vulnerabilidade, isso poderia ser interpretado como um indício de que existe externalização; isso seria observado por valores significativos nas interações entre IPVS e repetência. Porém, a maioria das interações entre IPVS da escola e repetência não é estatisticamente significativa (Tabela 12) ${ }^{22}$.

Tabela 12 - Fatores que influenciam a probabilidade de saída de uma escola - com interações

\begin{tabular}{|c|c|c|c|c|c|c|c|c|}
\hline Covariadas & \multicolumn{2}{|c|}{ Coorte 1} & \multicolumn{2}{|c|}{ Coorte 2} & \multicolumn{2}{|c|}{ Coorte 3} & \multicolumn{2}{|c|}{ Coorte 4} \\
\hline Mudou de escola no ano anterior & 0,005 & & 0,000 & & $-0,003$ & & 0,002 & \\
\hline IPVS da escola: 0 & 0,051 & & 0,068 & & $-0,209$ & & $-0,271$ & * \\
\hline IPVS da escola: 2 & 0,108 & & 0,106 & & 0,035 & & $-0,136$ & \\
\hline IPVS da escola: 3 & 0,105 & & 0,030 & & 0,058 & & $-0,199$ & ** \\
\hline IPVS da escola: 4 & $-0,113$ & & 0,191 & & $-0,235$ & * & $-0,367$ & $\star \star \star$ \\
\hline IPVS da escola: 5 & 0,116 & & 0,087 & & 0,083 & & $-0,081$ & \\
\hline IPVS da escola: 6 & 0,542 & 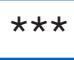 & 0,205 & & 0,025 & & $-0,148$ & \\
\hline Aluno repetiu de ano & 0,005 & & 0,041 & & 0,036 & & 0,024 & $\star \star$ \\
\hline $\begin{array}{c}\text { Interação: IPVS da escola } 0 \text { e aluno } \\
\text { repetiu de ano }\end{array}$ & $-0,037$ & & $-0,055$ & & $-0,009$ & & 0,010 & \\
\hline $\begin{array}{c}\text { Interação: IPVS da escola } 2 \text { e aluno } \\
\text { repetiu de ano }\end{array}$ & 0,017 & & 0,036 & & 0,011 & & 0,002 & \\
\hline $\begin{array}{c}\text { Interação: IPVS da escola } 3 \text { e aluno } \\
\text { repetiu de ano }\end{array}$ & 0,014 & & 0,051 & & 0,025 & & 0,024 & * \\
\hline $\begin{array}{c}\text { Interação: IPVS da escola } 4 \text { e aluno } \\
\text { repetiu de ano }\end{array}$ & 0,009 & & 0,049 & & 0,024 & & 0,004 & \\
\hline $\begin{array}{l}\text { Interação: IPVS da escola } 5 \text { e aluno } \\
\text { repetiu de ano }\end{array}$ & 0,030 & * & 0,048 & & $-0,001$ & & $-0,004$ & \\
\hline $\begin{array}{c}\text { Interação: IPVS da escola } 6 \text { e aluno } \\
\text { repetiu de ano }\end{array}$ & $-0,013$ & & $-0,041$ & & $-0,030$ & & $-0,062$ & ** \\
\hline Taxa de distorção idade-série do EF & $-0,002$ & $\star \star \star *$ & 0,000 & & $-0,001$ & & $-0,002$ & $\star \star \star$ \\
\hline Aluno mudou de CEP & 0,114 & $\star \star \star$ & 0,150 & $\star \star \star *$ & 0,102 & $\star * \star$ & 0,111 & 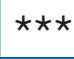 \\
\hline Aluno usa TEG & 0,052 & $\star \star \star *$ & 0,046 & 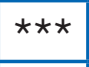 & 0,030 & $\star * \star$ & 0,028 & 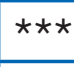 \\
\hline IPVS do aluno: 0 & 0,045 & & 0,027 & & $-0,008$ & & 0,003 & \\
\hline IPVS do aluno: 2 & 0,016 & & 0,060 & * & $-0,019$ & & $-0,007$ & \\
\hline IPVS do aluno: 3 & 0,035 & & 0,036 & & $-0,014$ & & $-0,003$ & \\
\hline IPVS do aluno: 4 & 0,034 & & 0,069 & $\star \star$ & 0,002 & & $-0,001$ & \\
\hline IPVS do aluno: 5 & 0,039 & * & 0,040 & & $-0,008$ & & 0,005 & \\
\hline IPVS do aluno: 6 & 0,030 & & 0,036 & & 0,001 & & $-0,007$ & \\
\hline IPVS do aluno: 7 & 0,080 & * & $-0,074$ & $\star \star$ & 0,109 & $\star \star \star$ & 1,090 & $\star \star \star$ \\
\hline
\end{tabular}

Fonte: Elaborada pelos autores com dados da SME.

22 Pelo teste $\mathrm{F}$ da hipótese de que os coeficientes das interações entre o IPVS da escola e a repetência e o coeficiente da repetência são simultaneamente iguais a zero. 
Notas: Todas as regressões contêm efeitos fixos de DRE e ano. Coorte 1: ingressantes no EF em 2008; coorte 2: ingressantes no EF em 2009; coorte 3: alunos que cursavam a $4^{\underline{a}}$ série em 2008; coorte 4: alunos que cursavam a $4^{\underline{a}}$ série em 2009.

*** Coeficiente significativo a $1 \% .{ }^{* \star}$ Coeficiente significativo a $5 \%$. ${ }^{\star}$ Coeficiente significativo a $10 \%$. Todos os outros coeficientes não são significativos.

Na Tabela 13 estão os resultados do modelo de probabilidade de chegada à escola com as interações incluídas. Nesse caso, temos que se os efeitos marginais da reprovação sobre a probabilidade de chegada forem maiores em escolas de alta vulnerabilidade, dados pelos valores dos coeficientes das interações entre IPVS e repetência, teríamos indícios de que há decantação. Porém, também aqui os valores não foram significativos estatisticamente. Assim, se alunos repetentes mudam mais de escola, não há um sentido claro dessa migração no sentido de irem para escolas mais ou menos vulneráveis. Essas regressões não revelam nenhum padrão de relação entre o IPVS da escola e a probabilidade de trocar de unidade nas coortes analisadas, com exceção de alunos de escolas de IPVS 6. Os alunos das coortes 1 e 2, que ingressaram no EF em 2008 e 2009, aparentam ter menos chances de chegar a uma escola de IPVS 6 - de vulnerabilidade muito alta. Já na análise da coorte 4, composta por alunos que cursavam a 4a série em 2009, a situação se inverte: cresce a probabilidade de um aluno chegar a uma escola quando esta tem IPVS 6. 
Tabela 13 - Fatores que influenciam a probabilidade de chegar à escola - com interações

\begin{tabular}{|c|c|c|c|c|c|c|c|c|}
\hline Covariadas & \multicolumn{2}{|c|}{ Coorte 1} & \multicolumn{2}{|c|}{ Coorte 2} & \multicolumn{2}{|c|}{ Coorte 3} & \multicolumn{2}{|c|}{ Coorte 4} \\
\hline Mudou de escola no ano anterior & 0,012 & $\star * *$ & $-0,006$ & & 0,004 & & 0,009 & $\star \star \star *$ \\
\hline IPVS da escola: 0 & 0,048 & & $-0,243$ & & 0,094 & & 0,079 & \\
\hline IPVS da escola: 2 & $-0,030$ & & $-0,153$ & & $-0,029$ & & 0,152 & * \\
\hline IPVS da escola: 3 & $-0,181$ & * & $-0,134$ & & $-0,076$ & & 0,175 & $\star \star$ \\
\hline IPVS da escola: 4 & $-0,081$ & & $-0,270$ & $\star \star$ & $-0,025$ & & 0,128 & \\
\hline IPVS da escola: 5 & $-0,039$ & & $-0,082$ & & $-0,072$ & & 0,165 & * \\
\hline IPVS da escola: 6 & $-0,472$ & $\star * *$ & $-0,595$ & $\star \star \star *$ & 0,020 & & 0,240 & ** \\
\hline Aluno repetiu de ano & 0,031 & * & $-0,006$ & & 0,014 & & 0,037 & 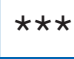 \\
\hline $\begin{array}{c}\text { Interação: IPVS da escola } 0 \text { e aluno } \\
\text { repetiu de ano }\end{array}$ & $-0,009$ & & 0,111 & * & 0,043 & & 0,058 & \\
\hline $\begin{array}{c}\text { Interação: IPVS da escola } 2 \text { e aluno } \\
\text { repetiu de ano }\end{array}$ & $-0,012$ & & 0,080 & $\star \star \star *$ & 0,033 & * & $-0,007$ & \\
\hline $\begin{array}{c}\text { Interação: IPVS da escola } 3 \text { e aluno } \\
\text { repetiu de ano }\end{array}$ & $-0,013$ & & 0,073 & $\star \star \star *$ & 0,036 & * & $-0,008$ & \\
\hline $\begin{array}{l}\text { Interação: IPVS da escola } 4 \text { e aluno } \\
\text { repetiu de ano }\end{array}$ & $-0,009$ & & 0,116 & $\star \star \star$ & 0,043 & ** & $-0,010$ & \\
\hline $\begin{array}{c}\text { Interação: IPVS da escola } 5 \text { e aluno } \\
\text { repetiu de ano }\end{array}$ & $-0,005$ & & 0,030 & & 0,029 & & $-0,014$ & \\
\hline $\begin{array}{c}\text { Interação: IPVS da escola } 6 \text { e aluno } \\
\text { repetiu de ano }\end{array}$ & $-0,006$ & & 0,071 & * & 0,032 & & $-0,036$ & \\
\hline Taxa de distorção idade-série do EF & 0,005 & $\star \star \star$ & 0,017 & $\star \star \star$ & 0,000 & & $-0,002$ & 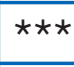 \\
\hline Aluno mudou de CEP & 0,107 & $\star \star \star x$ & 0,150 & $\star \star \star$ & 0,098 & $\star \star \star$ & 0,107 & $\star \star \star ~$ \\
\hline Aluno usa TEG & $-0,044$ & $\star \star \star *$ & $-0,019$ & $* \star *$ & $-0,017$ & 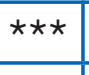 & $-0,041$ & 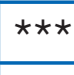 \\
\hline IPVS do aluno: 0 & 0,063 & & $-0,094$ & & $-0,017$ & & $-0,026$ & \\
\hline IPVS do aluno: 2 & 0,027 & & $-0,040$ & & $-0,024$ & & $-0,004$ & \\
\hline IPVS do aluno: 3 & 0,026 & & 0,003 & & $-0,032$ & & $-0,013$ & \\
\hline IPVS do aluno: 4 & 0,028 & & $-0,016$ & & $-0,035$ & & $-0,012$ & \\
\hline IPVS do aluno: 5 & 0,025 & & $-0,023$ & & $-0,047$ & & $-0,023$ & \\
\hline IPVS do aluno: 6 & 0,015 & & $-0,008$ & & $-0,019$ & & $-0,007$ & \\
\hline IPVS do aluno: 7 & 0,135 & $\star \star \star$ & 0,121 & $\star \star \star$ & & & 0,914 & $\star \star \star ~$ \\
\hline
\end{tabular}

Fonte: Elaborada pelos autores com dados da SME.

Notas: Todas as regressões contêm efeitos fixos de DRE e ano. Coorte 1: ingressantes no EF em 2008; coorte 2: ingressantes no EF em 2009; coorte 3: alunos que cursavam a $4^{\text {a }}$ série em 2008; coorte 4: alunos que cursavam a $4^{\underline{a}}$ série em 2009.

\footnotetext{
*** Coeficiente significativo a $1 \%$. ${ }^{* \star}$ Coeficiente significativo a $5 \%$. ${ }^{*}$ Coeficiente significativo a $10 \%$. Todos os outros coeficientes não são significativos.
} 
Tomando os resultados obtidos pela análise do modelo de painel dinâmico, pode-se dizer que os alunos repetentes tendem a trocar mais de escola, porém eles não tendem a ir para escolas mais vulneráveis nem menos vulneráveis. Portanto, não há indícios de que haja um movimento de exteriorização dos alunos repetentes para escolas mais vulneráveis.

Ressalta-se que a mudança de CEP do aluno explica a probabilidade de trocar de escola em todas as especificações, com efeitos marginais entre 10 a 15 pontos percentuais. Ademais, a TEG se associa positivamente com a chance de saída e negativamente com a chance de chegada, o que é intuitivo, tendo em vista que, se houver vaga em escola próxima da moradia do estudante e ele for para essa unidade, a RMESP deixará de custear o transporte escolar (aluno teria TEG na escola de partida e deixaria de tê-la na escola de destino). Notase que não há um padrão de relação entre o IPVS da escola e a probabilidade de trocar de unidade nas coortes analisadas ${ }^{23}$.

Os resultados apontam que os alunos repetentes tendem a trocar mais de escolas, porém não há um sentido claro dessa migração para escolas mais vulneráveis nem menos - isto é, não há um padrão de relação entre o IPVS da escola e a probabilidade de trocar de unidade nas coortes analisadas.

\section{Modelos DE PoISSON}

Os modelos de Poisson foram estimados para explicar os graus de recepção (indegree) e de doação (outdegree) de redes de movimentação de alunos entre escolas. Como será visto adiante, há fluxos de alunos entre as escolas municipais da RMESP associados à mudança de residência (CEP) dos alunos e à repetência. As redes foram geradas no intuito de identificar fatores associados a uma maior ou menor "doação" e "recepção" de alunos pelas escolas municipais, porém agora apenas com os alunos que mudaram de escola de um ano para o outro e permaneceram na RMESP, separados nos seguintes grupos: a) alunos que mudaram de CEP (tendo repetido de ano ou não); b) alunos que não mudaram de (EP e repetiram de ano; e c) alunos que não mudaram de CEP e não repetiram de ano. Esses fluxos foram examinados separadamente, pois envolvem diferentes motivações para mudança. 0 primeiro fluxo de alunos é gerado por uma mudança de endereço e o desejo de estudar perto de casa. Os alunos repetentes podem passar por uma pressão da escola para que sejam transferidos. Já os alunos que não repetiram

23 Os modelos com dois lags (não reportados) corroboram os resultados gerais dos modelos com um lag. 
nem mudaram de CEP podem estar mudando de escola por conta da ação voluntária da família de buscar uma escola mais adequada ou por processos de expulsão velada realizados pela escola.

Nas redes de movimentação de alunos entre escolas, os nós são as escolas e os vínculos refletem a existência de trocas de alunos. Esta análise toma a escola como unidade, isto é, verificamos as trocas entre escolas. Se duas escolas trocam alunos, independentemente do número de alunos trocados, elas formam um par. Uma escola que “doa” muito, por exemplo, é uma escola que "enviou" alunos para muitas outras, isto é, uma escola que formou muitos pares. A ideia é identificar algum viés no destino dos alunos, em que alunos com melhor desempenho acadêmico ou menos vulneráveis deixariam escolas mais "vulneráveis" em direção a escolas menos "vulneráveis". Não se está olhando, nesse momento, para a quantidade de alunos trocados, mas para as redes de trocas estabelecidas.

As variáveis explicativas (ou covariadas) desse modelo são características das escolas - taxas de repetência, abandono e taxa de distorção idade-série do EF (indicadores da qualidade da escola), cluster $^{24}$ da escola (indicador alternativo de vulnerabilidade) - com o controle pelo número de matrículas de EF como offset. Geraram-se redes para cada fluxo em 2009 e 2011, e para cada etapa (EF1 e EF2). Apresentamos a forma funcional do modelo estimado no Apêndice II.

Os clusters foram gerados com base em similaridades e dissimilaridades do corpo discente das escolas, agrupando-as de acordo com algumas características: a distribuição dos alunos pelas classes econômicas (seguindo o Critério Brasil25), o IPVS de moradia dos alunos e a porcentagem de negros em cada escola.

A partir disso, a análise de cluster classificou as escolas em quatro graus diferentes de vulnerabilidade, considerando características dos alunos de cada escola: porcentagens nas classes econômicas do Critério Brasil,

24 Foi realizada uma Análise de Cluster via o método da partição k-means, pelo qual foram gerados de 2 a 15 grupos. Posteriormente, realizando uma análise de ganhos na homogeneidade interna via Manova (Análise de Variâncias Multivariada) em função do número de grupos, determinou-se a quantidade de grupos adequada.

25 O objetivo do Critério de Classificação Econômica Brasil (Critério Brasil), da Associação Brasileira de Empresas de Pesquisa (Abep), é estimar o poder de compra de pessoas e famílias residentes na área urbana. Para tanto, classifica os indivíduos em oito classes econômicas - A1, A2, B1, B2, C1, C2, D e E - com potencial de consumo decrescente (ABEP, 2016). 
porcentagem de negros (dados da Prova Brasil) e em cada nível de IPVS de moradia (SME). Nas escolas do cluster I está o grupo mais vulnerável, sobretudo economicamente (maiores percentagens de alunos das classes D e E). O cluster II é menos vulnerável economicamente do que o I, mas ambos têm a distribuição do IPVS de moradia dos alunos semelhante (maior vulnerabilidade que clusters III e IV). O cluster III apresenta distribuição do IPVS dos alunos similar à do IV, porém agrupa mais alunos da classe C1 e negros. O cluster IV (com mais alunos de locais de baixa vulnerabilidade) contém as escolas com corpo discente menos vulnerável em todas as dimensões. Para mais detalhes sobre a metodologia utilizada nos clusters, ver Apêndice III.

Para o fluxo de alunos que repetiram e não mudaram de CEP, este exercício é uma metodologia alternativa para verificar se há externalização ou decantação desses alunos na escala intrarrede. Se de fato esses fenômenos ocorrem, deveríamos observar escolas com menor vulnerabilidade doando alunos repetentes e escolas mais vulneráveis recebendo-os. Aqui olhamos a vulnerabilidade das escolas pelos clusters a que ela está associada, portanto a vulnerabilidade é dada pela porcentagem de alunos em cada nível de IPVS e de classe econômica e pelo porcentual de negros no corpo discente.

Os resultados não mostram o padrão sugerido pela hipótese de pesquisa não há diferenças de indegree por cluster (não há clusters de escolas mais ou menos vulneráveis recebendo alunos de uma rede maior de escolas em relação a escolas de outros clusters). Porém, observa-se que nas escolas do EF2, quanto maior a taxa de distorção idade-série, maior o indegree $-1 \%$ a mais de taxa de distorção idade-série na escola aumenta entre 4\% e 5\% o número de escolas das quais recebe alunos. Isso indica que essas podem ser escolas que decantam alunos repetentes, pois há um fluxo deles em sua direção (Tabela 14).

Tabela 14 - Escolas que receberam alunos que não mudaram de CEP e repetiram

\begin{tabular}{|c|c|c|c|c|c|c|c|c|}
\hline Variável & \multicolumn{2}{|c|}{ EF1 - 2009} & \multicolumn{2}{|c|}{ EF1 - 2011} & \multicolumn{2}{|c|}{ EF2 - 2009} & \multicolumn{2}{|c|}{ EF2 - 2011} \\
\hline Constante & $-7,239$ & * & $-7,200$ & * & $-7,584$ & * & $-7,230$ & * \\
\hline rep_cent & $-0,012$ & & $-0,010$ & & 0,001 & & $-0,010$ & \\
\hline$a b \_c$ & 0,008 & & $-0,010$ & & 0,044 & & $-0,010$ & \\
\hline TDI_EF & 0,019 & & 0,020 & & 0,055 & $\pi$ & 0,040 & * \\
\hline clus & 0,294 & & 0,130 & & 0,264 & & 0,130 & \\
\hline clu & $-0,047$ & & $-0,010$ & & 0,173 & & 0,160 & \\
\hline clust & $-0,137$ & & $-0,180$ & & 0,154 & & 0,140 & \\
\hline
\end{tabular}

Fonte: Elaborada pelos autores com dados da SME e do Inep. 
*** Coeficiente significativo a $1 \% .{ }^{* *}$ Coeficiente significativo a $5 \%$. ${ }^{*}$ Coeficiente significativo a $10 \%$. Todos os outros coeficientes não são significativos.

Observa-se que escolas de vulnerabilidade média (e não baixa) tendem a doar alunos repetentes para mais escolas que as unidades mais vulneráveis apenas em algumas coortes: EF1 em 2009 e de EF2 em 2011; no outro ano de cada etapa os coeficientes dos clusters não são significativos (Tabela 15, coeficientes da variável cluster 4).

Tabela 15 - Escolas que doaram alunos que não mudaram de CEP e repetiram

\begin{tabular}{|c|c|c|c|c|c|c|c|c|}
\hline Variável & \multicolumn{2}{|c|}{ EF1 - 2009} & \multicolumn{2}{|c|}{ EF1 - 2011} & \multicolumn{2}{|c|}{ EF2 - 2009} & \multicolumn{2}{|c|}{ EF2 - 2011} \\
\hline Constante & $-6,968$ & * & $-7,140$ & * & $-7,010$ & * & $-6,730$ & * \\
\hline rep_cent & 0,002 & & 0,005 & & $-0,020$ & & $-0,020$ & \\
\hline ab_cent & 0,161 & * & 0,094 & & 0,110 & * & 0,110 & * \\
\hline TDI_EF & 0,005 & & 0,013 & & 0,020 & & $-0,010$ & \\
\hline cluster 2 & $-0,092$ & & 0,055 & & 0,340 & & 0,000 & \\
\hline cluster 3 & $-0,105$ & & $-0,123$ & & $-0,090$ & & 0,170 & \\
\hline cluster 4 & 0,309 & * & $-0,006$ & & 0,070 & & 0,240 & * \\
\hline
\end{tabular}

Fonte: Elaborada pelos autores com dados da SME e do Inep.

*** Coeficiente significativo a $1 \%$. ** Coeficiente significativo a $5 \%$. * Coeficiente significativo a $10 \%$. Todos os outros coeficientes não são significativos.

Para o fluxo de alunos que mudaram de endereço (Tabela 16), os resultados não mostram um padrão claro de escola receptora, provavelmente porque esse fluxo se associa a motivos muito diversos para a troca de escola, relacionados a questões familiares e de renda.

Tabela 16 - Escolas que receberam alunos que mudaram de CEP

\begin{tabular}{|c|c|c|c|c|c|c|c|c|}
\hline Variável & \multicolumn{2}{|c|}{ EF1 - 2009} & \multicolumn{2}{|c|}{ EF1 - 2011} & \multicolumn{2}{|c|}{ EF2 - 2009} & \multicolumn{2}{|c|}{ EF2 - 2011} \\
\hline Constante & $-5,810$ & * & $-5,350$ & * & $-5,672$ & * & $-5,980$ & * \\
\hline rep_cent & $-0,040$ & * & $-0,030$ & * & $-0,067$ & * & $-0,060$ & * \\
\hline ab_cent & $-0,020$ & & $-0,010$ & & 0,004 & & $-0,030$ & \\
\hline TDI_EF & 0,010 & & 0,010 & & 0,012 & & 0,030 & * \\
\hline cluster 2 & $-0,080$ & & $-0,030$ & & $-0,109$ & & 0,120 & * \\
\hline cluster 3 & 0,060 & & 0,040 & & $-0,110$ & & 0,270 & * \\
\hline cluster 4 & 0,260 & * & 0,030 & & 0,018 & & 0,160 & * \\
\hline
\end{tabular}

Fonte: Elaborada pelos autores com dados da SME e do Inep.

${ }^{\star * *}$ Coeficiente significativo a $1 \% .{ }^{* *}$ Coeficiente significativo a $5 \% .{ }^{*}$ Coeficiente significativo a $10 \%$. Todos os outros coeficientes não são significativos. 
BATISTA, Antônio Augusto Gomes; THOMAZINHO, Gabriela; KASMIRSKI, Paula Reis;

MELLO, Hivy Damasio Araújo; GUARNIERI, Fernando Henrique Eduardo.

O mesmo acontece em relação às escolas que doaram alunos que mudaram de CEP: não há um padrão claro, dado que poucos coeficientes são significativos (Tabela 17).

Tabela 17 - Escolas que doaram alunos que mudaram de CEP

\begin{tabular}{|c|c|c|c|c|c|c|c|c|}
\hline Variável & \multicolumn{2}{|c|}{ EF1 - 2009} & \multicolumn{2}{|c|}{ EF1 - 2011} & \multicolumn{2}{|c|}{ EF2 - 2009} & \multicolumn{2}{|c|}{ EF2 - 2011} \\
\hline Constante & $-5,871$ & * & $-5,220$ & * & $-5,537$ & * & $-5,700$ & * \\
\hline rep_cent & $-0,018$ & & $-0,030$ & * & 0,000 & & $-0,020$ & * \\
\hline ab_cent & 0,002 & & 0,030 & & 0,040 & & 0,020 & \\
\hline TDI_EF & 0,022 & * & 0,000 & & 0,003 & & 0,010 & \\
\hline cluster 2 & $-0,109$ & & $-0,080$ & & $-0,302$ & * & $-0,110$ & \\
\hline clust & 0,084 & & $-0,010$ & & $-0,027$ & & $-0,020$ & \\
\hline cluster 4 & 0,157 & * & 0,090 & & 0,009 & & 0,140 & * \\
\hline
\end{tabular}

Fonte: Elaborada pelos autores com dados da SME e do Inep.

\footnotetext{
*** Coeficiente significativo a $1 \%$. ** Coeficiente significativo a $5 \%$. * Coeficiente significativo a $10 \%$. Todos os outros coeficientes não são significativos.
}

Por fim, resta o fluxo de alunos que não repetiram nem mudaram de CEP, cuja análise é interessante, pois provavelmente o aluno que muda de escola por iniciativa da família em busca de maior qualidade está nesse fluxo. Seria intuitivo esperar que o indegree fosse maior em escolas menos vulneráveis e o outdegree fosse maior em escolas mais vulneráreis. Porém, dentro desse fluxo também podem estar alunos não repetentes que passaram por processos de expulsão velada, e por isso migrariam de escolas menos vulneráveis para escolas mais vulneráveis. Em 2009, nas duas etapas, há evidência de que escolas menos vulneráveis recebem alunos desse fluxo de uma rede maior de escolas (Tabela 18).

Tabela 18 - Escolas que receberam alunos que não mudaram de CEP e não repetiram

\begin{tabular}{|c|c|c|c|c|c|c|c|c|}
\hline Variável & \multicolumn{2}{|c|}{ EF1 - 2009} & \multicolumn{2}{|c|}{ EF1 - 2011} & \multicolumn{2}{|c|}{ EF2 - 2009} & \multicolumn{2}{|c|}{$E F 2-2011$} \\
\hline Constante & $-5,770$ & * & $-5,640$ & * & $-6,250$ & * & $-5,835$ & * \\
\hline rep_cent & $-0,020$ & * & $-0,030$ & * & $-0,030$ & & $-0,032$ & * \\
\hline ab_cent & 0,030 & & 0,030 & & 0,050 & & 0,031 & \\
\hline TDI_EF & 0,020 & * & 0,010 & & 0,020 & * & 0,005 & \\
\hline cluster 2 & 0,240 & * & 0,090 & & $-0,020$ & & 0,084 & \\
\hline cluster 3 & 0,090 & & $-0,040$ & & 0,180 & * & 0,083 & \\
\hline cluster 4 & $-0,060$ & & 0,020 & & $-0,020$ & & 0,055 & \\
\hline
\end{tabular}

Fonte: Elaborada pelos autores com dados da SME e do Inep. 
*** Coeficiente significativo a $1 \% .{ }^{* *}$ Coeficiente significativo a $5 \% .{ }^{*}$ Coeficiente significativo a $10 \%$. Todos os outros coeficientes não são significativos.

Já em relação ao padrão das escolas doadoras, para o EF2, em 2009 e 2011, há evidência de que escolas menos vulneráveis doam para um número maior de escolas (Tabela 19).

Tabela 19 - Escolas que doaram alunos que não mudaram de CEP e não repetiram

\begin{tabular}{|c|c|c|c|c|c|c|c|c|}
\hline Variável & \multicolumn{2}{|c|}{ EF1 - 2009} & \multicolumn{2}{|c|}{ EF1 - 2011} & \multicolumn{2}{|c|}{ EF2 - 2009} & \multicolumn{2}{|c|}{ EF2 - 2011} \\
\hline Constante & $-5,546$ & * & $-5,550$ & * & $-6,370$ & * & $-5,940$ & * \\
\hline rep_cent & 0,010 & & $-0,030$ & * & $-0,010$ & & $-0,040$ & * \\
\hline ab_cent & 0,071 & * & 0,050 & * & 0,040 & & 0,070 & * \\
\hline TDI_EF & 0,002 & & 0,010 & & 0,030 & * & 0,010 & \\
\hline cluster 2 & $-0,093$ & & $-0,040$ & & 0,140 & & 0,060 & \\
\hline cluster 3 & 0,050 & & $-0,020$ & & 0,320 & * & 0,090 & \\
\hline cluster 4 & 0,100 & & 0,080 & & 0,300 & * & 0,140 & * \\
\hline
\end{tabular}

Fonte: Elaborada pelos autores com dados da SME e do Inep.

${ }^{\star * \star}$ Coeficiente significativo a $1 \% .{ }^{*}$ Coeficiente significativo a $5 \% .{ }^{*}$ Coeficiente significativo a $10 \%$. Todos os outros coeficientes não são significativos.

Os resultados obtidos pelo modelo de Poisson não indicam uma movimentação clara dos alunos em alguma direção específica e/ou características associadas às escolas que mais recebem (reprovação, abandono, TDI, clusters de vulnerabilidade). A grande variação no valor e no sinal dos coeficientes de uma mesma variável de um ano para o outro e de uma etapa para a outra indica que há pouco padrão nessa variação. Em outros termos, não é possível identificar algum viés que explique que uma escola receba ou doe para mais ou menos escolas.

\section{CONCLUSÃO}

A regra geral de matrícula é a proximidade da residência - setorização. Os dados indicam que, na escala intrarrede, ela de fato restringe 0 comportamento das famílias e das escolas na RMESP, pois a rotatividade das escolas municipais é baixa (tendo em vista o padrão das redes municipais das demais capitais do país) e aumentou pouco no período estudado (2008 a 2013). Além disso, a variabilidade das taxas é baixa e não há diferenças substanciais entre DREs ou entre escolas de diferentes perfis. A mudança de 
endereço e o transporte escolar gratuito são fatores explicativos robustos da probabilidade de trocar de escola, mais um indício de que a setorização é fator inibidor da movimentação de alunos.

Usamos três metodologias para investigar a existência de escolas que "exteriorizam" e que "decantam" alunos, e elas revelaram que tais fenômenos, ligados a relações de interdependência competitiva detectadas em pesquisas em escala microssocial, não ocorrem, em escala macrossocial, na RMESP apenas de forma localizada. A análise de tais relações de interdependência, mais claramente identificadas em pesquisas anteriores na escala microssocial, demanda, porém, extrema atenção, sobretudo por se tratar de relações que mudam conforme o contexto e, assim, podem ser identificadas em alguns momentos (no caso aqui, em anos pontuais) dentro da análise. A análise de clusters, por exemplo, pelo método privilegiado, evidenciou relações ligadas à vulnerabilidade e aos fenômenos de “decantação" e "exteriorização" de alunos, mas não salientam características das escolas. De modo que ainda demandam maior investigação outros modos de relações de interdependência competitiva em contextos e momentos específicos nos quais esse fenômeno poderia ser evidenciado. Assim, poderemos compreender, talvez, momentos em que tais relações são ativadas, políticas que podem favorecê-las ou não (considerando, ainda, reações das escolas), efeito de mudanças demográficas, entre outros.

Por fim, a correlação positiva entre o IPVS da escola e o IPVS dos seus alunos indica que estudantes que moram em regiões mais vulneráveis estudam em escolas localizadas em áreas também mais vulneráveis. Em uma escola de IPVS 1 (baixa vulnerabilidade), o percentual de alunos que moram em regiões com IPVS de 1 a 3 (baixa vulnerabilidade) é superior em 30 pontos percentuais em comparação com uma escola de IPVS 6.

A setorização da matrícula, em um contexto marcado pelas desigualdades socioespaciais, como o de São Paulo, pode estar acentuando a segregação escolar ao concentrar em suas unidades populações com características sociodemográficas que tendem à homogeneidade.

Os resultados das regressões de painel dinâmico indicam que alunos repetentes tendem a mudar mais de escola. Um aluno que repete tem entre 2,0 e 7,5 pontos percentuais a mais de probabilidade de mudar de escola. Porém, não há indícios que apontem que alunos repetentes migrem para escolas localizadas em entornos mais vulneráveis. 


\section{Competitive inderdependence and students' movement between schools: the São Paulo municipal network case (2008-2013)}

Abstract: This article analyzes how school changes by elementary school students from São Paulo municipal network take place, in order to measure competitive interdependence relations between schools - understood as changes they make betweem themselves of students originally enrolled in them. Enrolment data for years 2008 and 2013 were subject of three analysis procedures: examining students' turnover rates; estimating likelihood of teachers leaving one school and going to another through a dynamic panel; and exploring schools social networks through Poisson's models. Results show that we cannot identify, in a intra-network scale, competitive interdependence relations, and that enrolment sectorization, in a context marked by sociospacial inequalities like São Paulo's, may be enhancing school segregation by concentrating in their units populations with socio-demographic features tending to homogeneity, since students living in more vulnerable regions end up studying in schools situated in more vulnerable areas too.

Key words: Students' selection. Educational inequalities. Territory effect. Competitive interdependence between schools. 


\section{Interdependencia competitiva y desplazamiento de alumnos entre escuelas: el caso de la red municipal de São Paulo (2008-2013)}

Resumen: En este artículo se analiza como se dan los cambios de escuela por los alumnos de la enseñanza fundamental de la Red Municipal de São Paulo, a fin de dimensionar las relaciones de interdependencia competitiva entre escuelas - comprendidas como los cambios que realizan entre sí de alumnos originalmente en ellas matriculados. Datos de registro para los años entre 2008 y 2013 fueron sometidos a tres procedimientos de análisis: el estudio de tasas de rotación; la estimación de la probabilidad de que los estudiantes salgan de una escuela y vayan hacia otra a través del panel dinámico; y la explotación de las redes sociales de escuelas, mediante modelos de Poisson. Los resultados demuestran que no se verifica, en el nivel dentro de la red, relaciones de interdependencia competitiva, y que la sectorización de la matrícula, en un contexto marcado por las desigualdades socioespaciales, como el de São Paulo, puede estar acentuando la segregación escolar al concentrar en sus unidades poblaciones con características sociodemográficas que tienden a la homogeneidad, una vez que alumnos que viven en regiones más vulnerables acaban por estudiar en escuelas ubicadas en áreas también vulnerables.

Palabras-clave: Selección de alumnos. Desigualdades educacionales. Efectoterritorio. Interdependencia competitiva entre escuelas. 


\section{REFERÊNCIAS}

ALVES, L. et al. Seleção velada em escolas públicas: práticas, processos e princípios geradores. Educação e Pesquisa, São Paulo, v. 41, n. 1, p. 137-152, jan./mar. 2015.

ALVES, L. et. al. Remoção de professores e desigualdades em territórios vulneráveis. Cadernos Cenpec, São Paulo: Cenpec, v. 4, n. 2, p. 122-145, dez. 2014. Disponível em: http://cadernos.cenpec.org.br/cadernos/index.php/ cadernos/article/view/292/289. Acesso em: 14 fev. 2018.

ARELLANO, M.; BOND, S. Some tests of specification for panel data: Monte Carlo evidence and an application to employment equations. The Review of Economic Studies, v. 58, n. 2, p. 277-297, abr. 1991.

ASSOCIAÇÃO BRASILEIRA DE EMPRESAS DE PESQUISA (ABEP). Critério de Classificação Econômica Brasil. Disponível em: http://www.abep.org/ criterio-brasil. Acesso em: 1ํago. 2016.

BATISTA, A. G.; CARVALHO-SILVA, H. Família, escola, território vulnerável. São Paulo: Cenpec, 2013.

BEN AYED, C. École ségrégative, école reproductive. Actes de La recherche en sciences sociales, Paris, n. 180, 2009.

BEN AYED, C. As desigualdades socioespaciais de acesso aos saberes: uma perspectiva de renovação da sociologia das desigualdades escolares? Educ. Soc., Campinas, v. 33, n. 120, p. 783-803, jul./set. 2012.

BEN AYED, C.; BROCCOLICHI, S. Quels liens entre réussite scolaire, inégalités sociales et lieu de scolarisation? Revue Ville École Intégration Diversité, Paris, n. 155, p. 66-71, déc. 2008.

BOURDIEU, P. Efeitos do lugar. In: BOURDIEU, P. (org.). Miséria do mundo. Petrópolis: Vozes, 1997. p. 159-166.

COSTA, M.; BARTHOLO, T. L. Padrões de segregação escolar no Brasil: um estudo comparativo entre capitais do país. Educ. Soc., Campinas, v. 35, n. 129, p. 1183-1203, out-dez. 2014.

DELVAUX, B.; VAN ZANTEN, A. Les établissements scolaires et leur espace local d`interdépendance. Revue Française de Pédagogie, n. 156, p. 5-8, jul./ set. 2006. 
ÉRNICA, M.; BATISTA, A. G. A escola, a metrópole e a vizinhança vulnerável. Cadernos de Pesquisa, v. 42, n. 1, p. 640-666, maio/ago. 2012.

FERRÃO, M. E. Retenção escolar e desenvolvimento cognitivo no ensino básico. In: NUNES, L. C. (org.). A escola e o desempenho dos alunos. Lisboa: Fundação Francisco Manuel dos Santos, 2015.

FUNDAÇÃO SISTEMA ESTADUAL DE ANÁLISE DE DADOS (SEADE). Dados do Índice Paulista de Vulnerabilidade Social. Versão 2010. Disponível em: http:// indices-ilp.al.sp.gov.br/view/index.php?prodCod=2. Acesso em: 10 jan. 2017.

FUNDAÇÃO SISTEMA ESTADUAL DE ANÁLISE DE DADOS (SEADE). Metodologia do Índice Paulista de Vulnerabilidade Social. São Paulo, 2013. Disponível em: http://indices-ilp.al.sp.gov.br/view/pdf/ipvs/metodologia.pdf. Acesso em: 10 jan. 2017.

HANUSHEK, E. A. et al. Disruption versus Tiebout improvement: the costs and benefits of switching schools. Journal of Public Economics, v. 88, n. 9-10, p. 1721-1746, 2004.

INSTITUTO NACIONAL DE ESTUDOS E PESQUISAS EDUCACIONAIS ANÍSIO TEIXEIRA (INEP). Indicadores Educacionais. Disponível em: http://portal.inep. gov.br/web/guest/indicadores-educacionais. Acesso em: 10 jan. 2017.

INSTITUTO NACIONAL DE ESTUDOS E PESQUISAS EDUCACIONAIS ANÍSIO TEIXEIRA (INEP). Microdados do Censo Escolar e da Prova Brasil. Disponível em: http://portal.inep.gov.br/web/guest/microdados. Acesso em: 10 jan. 2017.

REBELO, J. A. S. Efeitos da retenção escolar, segundo os estudos científicos, e orientações para uma intervenção eficaz: Uma revisão. Revista Portuguesa de Pedagogia, v. 43, n. 1, p. 27-52, 2009.

RIBEIRO, L. C. Q; KAZTMAN, R. (org.). A cidade contra a escola? Segregação urbana e desigualdades educacionais em grandes cidades da América Latina. Rio de Janeiro: Letra Capital; Montevidéu: Ippes, 2008.

RIBEIRO, L. C. Q. et al. (org.). Desigualdades urbanas, desigualdades escolares. Rio de Janeiro: Letra Capital: Observatório das Metrópoles: IPPUR/UFRJ, 2010.

RUMBERGER, R. W. The causes and consequences of student mobility. Journal of Negro Education, v. 72, n. 1, p. 6-21, 2003. 
SÃO PAULO (Estado e Município). Portaria Conjunta SEE/SME n. 1, de 23 de julho de 2007. Diário Oficial da Cidade de São Paulo. São Paulo, 2007.

SÃO PAULO (Estado e Município). Portaria Conjunta SEE/SME n. 1, de 7 de agosto de 2008. Diário Oficial da Cidade de São Paulo. São Paulo, 2008.

SÃO PAULO (Estado e Município). Portaria Conjunta SEE/SME n. 1, de 13 de agosto de 2009. Diário Oficial da Cidade de São Paulo. São Paulo, 2009.

SÃO PAULO (Estado e Município). Portaria Conjunta SEE/SME n. 1, de 25 de agosto de 2010. Diário Oficial da Cidade de São Paulo. São Paulo, 2010.

SÃO PAULO (Estado e Município). Portaria Conjunta SEE/SME n. 1, de 24 de agosto de 2011. Diário Oficial da Cidade de São Paulo. São Paulo, 2011.

SÃO PAULO (Estado e Município). Portaria Conjunta SEE/SME n. 1, de 15 de agosto de 2012. Diário Oficial da Cidade de São Paulo. São Paulo, 2012.

SÃO PAULO (Município). Lei n. 13.697, de 22 e dezembro de 2003. Diário Oficial da Cidade de São Paulo. São Paulo, 2003.

VAN ZANTEN, A. L'école de la périphérie: scolarité et ségrégation en banlieue. Paris: PUF, 2001.

VAN ZANTEN, A. Efeitos da concorrência sobre as atividades dos estabelecimentos escolares. Cadernos de Pesquisa, São Paulo, v. 35, n. 126, p. 565-593, set./dez. 2005.

SOBRE OS AUTORES:

Antônio Augusto Gomes Batista é doutor em Educação pela Universidade Federal de Minas Gerais. Foi coordenador da Coordenação de Desenvolvimento de Pesquisas do Cenpec entre 2011 e 2018, em cuja instituição integra o conselho de administração desde 2018. E-mail: antonio.batista@icloud.com

Gabriela Thomazinho é mestre em Educação pela Universidade de São Paulo. Atualmente atua como consultora do Imagem da Vida. Colaborou com o Cenpec nos estudos referentes à pesquisa “Interpendência competitiva entre escolas” em 2017 e 2018. E-mail: gabriela.thomazinho@gmail.com 
Paula Reis Kasmirski é mestre em Economia pela Faculdade de Economia e Administração da Universidade de São Paulo (FEA/USP) e doutoranda em Economia pela Fundação Getulio Vargas (FGV). Foi pesquisadora do Cenpec entre 2013 e 2016. E-mail: prkasmirski@gmail.com

Hivy Damasio Araújo Mello é doutora em Sociologia pela Universidade Estadual de Campinas. Realiza pós-doutoramento na mesma universidade. Foi pesquisadora do Cenpec entre 2014 e 2017. E-mail: hivy_mello@gmail.com

Fernando Henrique Eduardo Guarnieri é doutor em Ciência Política pela Universidade de São Paulo e professor no Instituto de Estudos Sociais e Políticos da Universidade do Estado do Rio de Janeiro (lesp/Uerj). Colaborou com o Cenpec nos estudos referentes à pesquisa “Interpendência competitiva entre escolas” em 2017. E-mail: fhguarnieri@gmail.com

Recebido em: novembro de 2018

Aceito em: março de 2019 


\section{APÊNDICE I}

Com base na literatura e em nossas restrições em termos de dados, estimamos modelos com a forma funcional a seguir:

$$
\mathrm{yit}_{\mathrm{it}}=\mathrm{ay} \mathrm{i}, \mathrm{t}-\mathrm{1}+\mathrm{xit} \mathrm{B}+\mathrm{Ci}+\mathrm{e}_{\mathrm{it}}
$$

Onde,

yit, nossa variável dependente é uma variável binária que indica se o aluno saiu (no primeiro modelo) ou chegou (no segundo modelo) a uma escola entre t e $t+1$, sendo t o ano base.

yi,t-1, nossas variáveis explicativas, são a variável dependente defasada (ou lag, isto é, o valor da variável no período anterior, indica se o aluno saiu ou chegou a uma escola em t-1, sendo t o ano base),

xit contém características do aluno $i$ que variam no tempo como IPVS da moradia, se mudou de endereço, se repetiu e se usa TEG; atributos da escola de que ele partiu (no modelo de saída) ou a qual chegou (no modelo de chegada) como IPVS da escola e distorção idade-série (TDI)); dummies de ano e de Diretoria Regional de Ensino (DRE),

ci é um efeito fixo do aluno (como dito, contém características discentes que não variam no tempo, como raça, sexo, se cursou Educação Infantil, escolaridade da mãe),

it é um erro idiossincrático.

Usamos o estimador de Arellano e Bond (1991) por meio do Stata $14^{26}$.

\section{APÊNDICE II}

Os modelos de Poisson estimados são:

Onde denota indegree ou outdegree da escola, é a taxa de reprovação, é a taxa de abandono, é a taxa de distorção idade-série e é o cluster.

26 Estimação em um estágio com variância robusta e com cluster no aluno. 


\section{APÊNDICE III}

O cluster 1 (categoria omitida) apresenta-se como o grupo mais vulnerável, principalmente economicamente, com menor proporção de alunos das classes A1, A2 e B1 e o inverso para os alunos das classes D e E. Quanto à distribuição do IPVS de moradia de seus alunos, ela é um pouco parecida com a do Grupo 2. Ambos os grupos possuem cerca de $1 / 4$ de seus alunos em cada nível de IPVS. Isso mostra que esses dois grupos possuem alunos de locais de moradia mais vulneráveis do que os grupos 3 e 4, que possuem mais da metade de seus corpos discentes em locais de moradia de baixíssima ou muito baixa vulnerabilidade. Quanto à porcentagem de negros do Grupo 1, ela não é estatisticamente diferente da do Grupo 2, e apenas levemente maior que a do Grupo 4. Ela só difere substancialmente da do Grupo 3, que é menor.

Como dito anteriormente, o Grupo 2 tem características semelhantes ao Grupo 1 no que se refere à distribuição do IPVS dos alunos e à porcentagem de negros. Mas a distribuição do corpo discente desse grupo pelas classes econômicas é diferente, pois tem mais alunos nas classes $A$ e $B$ e menos nas C2, D e E.

As escolas do Grupo 4 apresentam uma distribuição do IPVS de moradia dos alunos bastante parecida com a do Grupo 3, portanto com maior proporção de alunos de locais pouco vulneráveis. Quando olhamos para a distribuição dos alunos pelas classes econômicas, observamos que ela tem uma grande porcentagem de alunos da classe $\mathrm{C} 1$, e menos alunos em ambas as pontas da distribuição. A porcentagem de negros desse grupo também é substancialmente maior do que a do Grupo 3.

O Grupo 3 contém as escolas com corpo discente menos vulnerável em todas as dimensões. Possui a maior proporção de alunos das classes A1, A2 e B1, a maior proporção de alunos cujo local de moradia é de baixíssima ou muito baixa vulnerabilidade e a menor porcentagem de IPVS de alta vulnerabilidade. Nesse grupo a porcentagem de negros é de $50 \%$, menor do que a de todos os outros, que giram em torno dos $62 \%$. 